\title{
MutS/MutL crystal structure reveals that the MutS sliding clamp loads MutL onto DNA
}

\author{
Flora S Groothuizen ${ }^{1}$, Ines Winkler ${ }^{2}$, Michele Cristóvão², Alexander Fish ${ }^{1}$, \\ Herrie HK Winterwerp ${ }^{1}$, Annet Reumer ${ }^{1}$, Andreas D Marx ${ }^{2}$, Nicolaas Hermans ${ }^{3}$, \\ Robert A Nicholls ${ }^{4}$, Garib N Murshudov ${ }^{4}$, Joyce HG Lebbink ${ }^{3,5}$, Peter Friedhoff ${ }^{2}$, \\ Titia K Sixma ${ }^{1 *}$
}

${ }^{1}$ Division of Biochemistry and CGC.nl, Netherlands Cancer Institute, Amsterdam, Netherlands; ${ }^{2}$ Institute for Biochemistry, Justus-Liebig-University, Giessen, Germany; ${ }^{3}$ Department of Genetics, Cancer Genomics Netherlands, Erasmus Medical Center, Rotterdam, Netherlands; ${ }^{4}$ Structural Studies Division, MRC Laboratory of Molecular Biology, Cambridge, United Kingdom; ${ }^{5}$ Department of Radiation Oncology, Erasmus Medical Center, Rotterdam, Netherlands

Abstract To avoid mutations in the genome, DNA replication is generally followed by DNA mismatch repair (MMR). MMR starts when a MutS homolog recognizes a mismatch and undergoes an ATP-dependent transformation to an elusive sliding clamp state. How this transient state promotes MutL homolog recruitment and activation of repair is unclear. Here we present a crystal structure of the MutS/MutL complex using a site-specifically crosslinked complex and examine how large conformational changes lead to activation of MutL. The structure captures MutS in the sliding clamp conformation, where tilting of the MutS subunits across each other pushes DNA into a new channel, and reorientation of the connector domain creates an interface for MutL with both MutS subunits. Our work explains how the sliding clamp promotes loading of MutL onto DNA, to activate downstream effectors. We thus elucidate a crucial mechanism that ensures that MMR is initiated only after detection of a DNA mismatch.

*For correspondence: t.sixma@nki.nl

Competing interests: The authors declare that no competing interests exist.

Funding: See page 20

Received: 28 January 2015 Accepted: 10 July 2015 Published: 11 July 2015

Reviewing editor: Leemor Joshua-Tor, Cold Spring Harbor Laboratory, United States

cc) Copyright Groothuizen et al. This article is distributed under the terms of the Creative Commons Attribution License, which permits unrestricted use and redistribution provided that the original author and source are credited.
DOI: 10.7554/eLife.06744.001

\section{Introduction}

To enable the correct and complete transfer of genetic information during cell division, DNA polymerases efficiently replicate the genome by pairing nucleotide bases opposite their complementary template base. However, despite the polymerase proofreading ability, incorrect nucleotides are occasionally incorporated into the new DNA strand, resulting in mutations when left uncorrected. To reduce the number of such mismatches and maintain genomic stability, replication is followed by DNA mismatch repair (MMR) in almost all cellular organisms (Kunkel and Erie, 2005; Jiricny, 2013). The initiation of this MMR system is evolutionarily conserved, although in eukaryotes heterodimeric homologs replace the bacterial homodimeric components. Defects in MMR result in a mutator phenotype and in humans in predisposition for cancer, known as Lynch syndrome or HNPCC (Lynch and de la Chapelle, 1999).

MMR is initiated when a MutS homolog binds to a mismatch. In this mismatch recognition step, the MutS dimer kinks the DNA at the site of the mismatch and stacks a phenylalanine onto the mispaired base (Lamers et al., 2000; Obmolova et al., 2000; Warren et al., 2007). Upon ATP binding MutS releases the mismatch (Allen et alı, 1997; Gradia et al., 1997) and travels as a 'sliding clamp' along the DNA helix (Gradia et al., 1999; Acharya et al, 2003; Jeong et al., 2011), and this specific state of 
elife digest The genetic code of DNA is written using four letters: "A", "C", "T", and "G". Molecules of DNA form a double helix in which the letters in the two opposing strands pair up in a specific manner-" $A$ " pairs with " $T$ ", and " $C$ " pairs with "G". A cell must replicate its DNA before it divides, and sometimes the wrong DNA letter can get added into the new DNA strand. If left uncorrected, these mistakes accumulate over time and can eventually harm the cell. As a result, cells have evolved several ways to identify these mistakes and correct them, including one known as "mismatch repair".

Mismatch repair occurs via several stages. The process starts when a protein called MutS comes across a site in the DNA where the letters are mismatched (for example, where an " $A$ " is paired with a " $\mathrm{C}$ ", instead of a "T"). MutS can recognize such a mismatch, bind it, and then bind to another molecule called ATP. MutS then changes shape and encircles the DNA like a clamp that can slide along the DNA. Only when it forms this "sliding clamp" state can MutS recruit another protein called MutL. This activity in turn triggers a series of further events that ultimately correct the mismatch. However, it remains poorly understood how MutS forms a clamp around DNA and how and why this state recruits MutL in order to start the repair.

To visualize this short-lived intermediate, Groothuizen et al. trapped the relevant complex in the presence of DNA containing a mismatch and then used a technique called X-ray crystallography to determine the three-dimensional structure of MutS bound to MutL. The structure reveals that two copies of MutS tilt across each other and open up a channel, which is large enough to accommodate the DNA. In this manner, MutS is able to form a loose ring around the DNA. The changes in the structure and the movement of the DNA to the new channel were confirmed using another technique, commonly referred to as FRET.

Groothuizen et al. observed that the movements in the MutS protein also serve to make the interfaces available that can recognize MutL. If these interfaces were disturbed, MutS and MutL were unable to associate with each other, which resulted in a failure to trigger mismatch repair. Further analysis revealed that that MutL binds to DNA only after MutS has recognised the mismatch and formed a clamp around it. This is the first time that the MutS clamp and the MutS/MutL complex have been visualized, and further work is now needed to understand how MutL triggers other events that ultimately repair the mismatched DNA.

DOI: 10.7554/eLife.06744.002

MutS is recognized by MutL or its homologs (Grilley et al., 1989; Prolla et al., 1994; Drotschmann et al., 1998; Acharya et al., 2003).

MutL proteins are constitutive dimers through their $\mathrm{C}$-terminal domains, while the $\mathrm{N}$-terminal ATPase domains reorganize and dimerize upon ATP binding (Grilley et al., 1989; Ban and Yang, 1998; Ban et al., 1999; Guarné et al., 2004). Once recruited by the MutS sliding clamp, the MutL homologs activate downstream repair. This includes the nicking of the newly replicated strand by a nuclease, which is either part of the MutL C-terminal domain (Kadyrov et al., 2006), or a separate protein such as MutH in Escherichia coli (Hall and Matson, 1999). MutL also activates UvrD in bacteria to unwind the DNA (Yamaguchi et al., 1998), after which the new DNA strand can be removed and re-replicated (Kunkel and Erie, 2005).

As loss of MutS homologs (MSH2, MSH3 and MSH6 in humans) or MutL homologs (MLH1 and PMS2 in humans) leads to mutator and/or cancer phenotypes, these proteins evidently have critical roles in mismatch repair and it is therefore important to understand their exact mechanism. Despite extensive studies (Gradia et al., 1999; Mendillo et al., 2005; Cho et al., 2012; Qiu et al., 2012), it is unclear how MutS achieves the sliding-clamp state, how this promotes MutL recognition and why this results in activation of the MutL protein.

Here, we trap the transient complex between MutS and MutL to resolve a crystal structure of the MutS sliding clamp bound to MutL. This is, to our knowledge, the first time that not only this MutS conformation but also the complex between MutS and MutL could be observed. We show how rearrangements in MutS promote interactions from both MutS subunits with a single MutL N-terminal domain, and how this domain is then positioned to load onto DNA running through a novel channel in the MutS dimer. We use biophysical methods to analyze the transient states and mechanistically 
understand the specificity and effect of MutL binding to MutS, and functional assays to address how this affects MMR initiation.

\section{Results}

\section{Structure of the MutS/MutL complex}

To trap the E. coli MutS/MutL complex we used site-specific chemical crosslinking of single-cysteine variants of MutS and MutL, with a flexible $\mathrm{BM}(\mathrm{PEO})_{3}$ crosslinker. First all cysteines in MutS and MutL were replaced and functionality of the resulting protein was confirmed (Giron-Monzon et al., 2004; Manelyte et al., 2006; Winkler et alo, 2011). Then single cysteines were introduced to find positions where crosslinking was dependent on sliding clamp formation. MutS D246C crosslinks specifically to MutL N131C only when a DNA mismatch and a nucleotide are present (Winkler et al., 2011; Figure 1A, Figure 1-figure supplement 1A), indicating that a complex relevant for MMR is trapped.

For structural studies, we scaled up the reaction and removed C-terminal domains from MutS and MutL (Figure 1A), to capture the complex between MutS ${ }^{\Delta C 800}$ D246C (which we will refer to as MutS ${ }^{\Delta C 800}$ ) and the $40 \mathrm{kDa} N$-terminal LN40 domain (Ban and Yang, 1998) of MutL N131C (which we will refer to as Mut ${ }^{\mathrm{LN} N 0}$ ). The proteins were crosslinked in the presence of mismatched DNA and ATP, followed by purification to obtain the protein, and then this cycle was repeated in order to obtain fully crosslinked material. This generated a complex where each MutS ${ }^{\Delta C 800}$ subunit in the dimer binds to a MutL ${ }^{\mathrm{LN} 40}$ monomer (Figure 1A, Figure 1-figure supplement 1B,C), which was sufficiently homogeneous and stable to allow crystallization.

We crystallized the MutS ${ }^{\Delta C 800} /$ MutL $^{\text {LN40 }}$ complex in the presence of DNA containing a G:T mismatch and the non-hydrolyzable ATP analog AMP-PNP (adenylyl-imidodiphosphate). The complex crystallized in several different space groups, diffracting to resolutions from 7.6 to $4.7 \AA$. In all crystal forms, we could elucidate the same structure of the protein complex (Figure 1B, Figure 1-figure supplements 2, Table 1), using parts of higher-resolution MutS ${ }^{\Delta C 800}$ and MutL ${ }^{\operatorname{LN}_{40}}$ structures for molecular replacement.

The crystal structure shows a novel conformation of MutS, in which the subunits in the dimer are tilted across each other by $\sim 30^{\circ}$, compared to the mismatch recognition state (Figure $\left.1 C, D\right)$. The subunits are tilted as a rigid body, but the C-terminal HTH domains hinging around residues 765-766, move with the opposite subunit, maintaining their role in stabilizing MutS dimers (Biswas et al., 2001). Meanwhile, the connector domains are rotated by $\sim 160^{\circ}$ around a hinge at residues $265-266$, which moves these domains out of the center of the molecule and packs them against the ATPase domains (Figure 1C,E). The mismatch-binding domain could not be resolved in the density, probably because it is flexible in this state. While the mismatch recognition state of MutS is asymmetric (Lamers et al., 2000), this MutL ${ }^{\mathrm{LN} 40}$-bound conformation shows a more symmetrical MutS ${ }^{\Delta C 800}$ dimer.

The MutL ${ }^{\mathrm{LN} 40}$ interaction with MutS ${ }^{\Delta C 800}$ involves two interfaces (Figure 1F). The first interface is formed by the largest $\beta$-sheet of the ATPase domain of MutL ${ }^{\mathrm{LN} 40}$, and the ATPase and core domains of one subunit of MutS $\mathrm{S}^{\Delta \mathrm{C} 800}$. The second interface involves the side of this same $\beta$-sheet and a looped-out helix of MutL ${ }^{\mathrm{LN} 40}$, and the newly positioned connector domain of the other MutS $\mathrm{SCBOO}^{\Delta u b u n i t . ~ E a c h ~}$ MutL ${ }^{\mathrm{LN} 40}$ monomer is therefore interacting with both subunits in the MutS ${ }^{\triangle \mathrm{CBO0}}$ dimer.

\section{Conformation of the MutS sliding clamp}

The novel conformation of MutS in our crystal structure reveals a rearrangement of the subunits in the MutS ${ }^{\Delta C 800}$ dimer, tilting around the interface formed by the two ATPase sites (Figure 1D, Video 1). The tilting creates a new MutS dimer interface of $\sim 500 \AA^{2}$ where the clamp domains cross over, partially from interactions between the helices themselves $\left(200 \AA^{2}\right)$, the rest from the ends of the clamp domains with the helices.

We observe nucleotide density in the ATP binding sites of both subunits in the MutS ${ }^{\Delta \mathrm{C} 800}$ dimer (Figure 2-figure supplement 1A), and since we crystallized the protein with AMP-PNP we modeled these nucleotides in the density. This type of ATP-induced tilting and increased packing of ATPase domains is more often observed upon ATP binding in ABC ATPases, such as ATP transporters, SMCs and RAD50 (Hopfner and Tainer, 2003). Based on comparison to RAD50 (Hopfner et al., 2000) we previously predicted a tilting motion (Lamers et al., 2004), and an open-to-closed transition has been supported by deuterium exchange mass spectrometry (Mendillo et al., 2010), but the crossing of the clamp domains of MutS and the effect that this has on DNA binding were unexpected. 
A

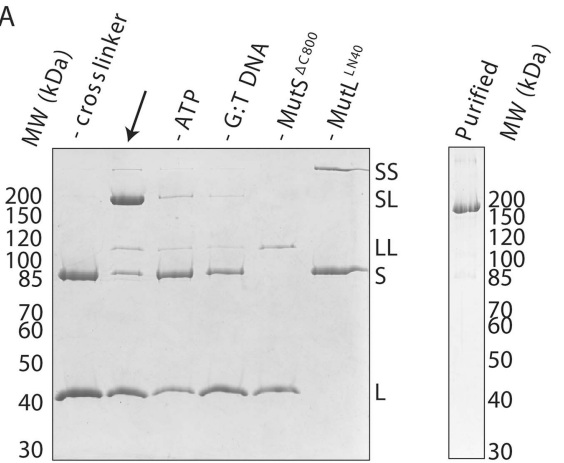

B

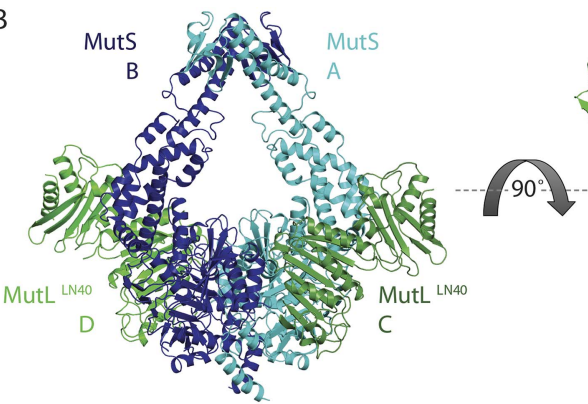

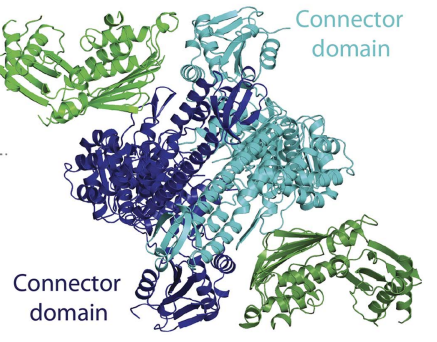

Single-cysteine MutS

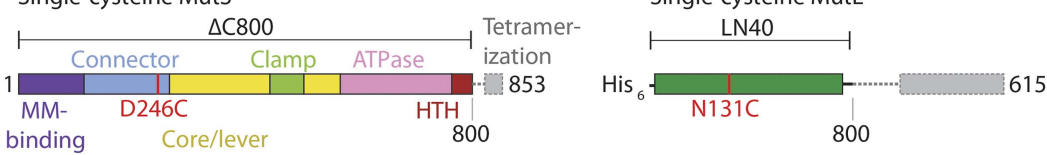

C
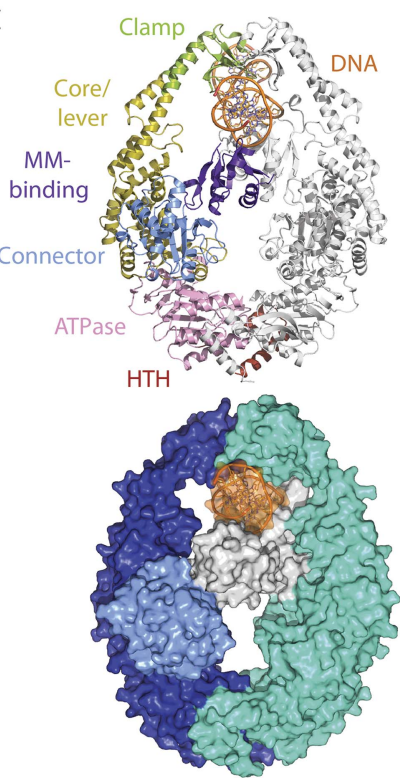

MutS ${ }^{\triangle C 800}$ bound to mismatched DNA

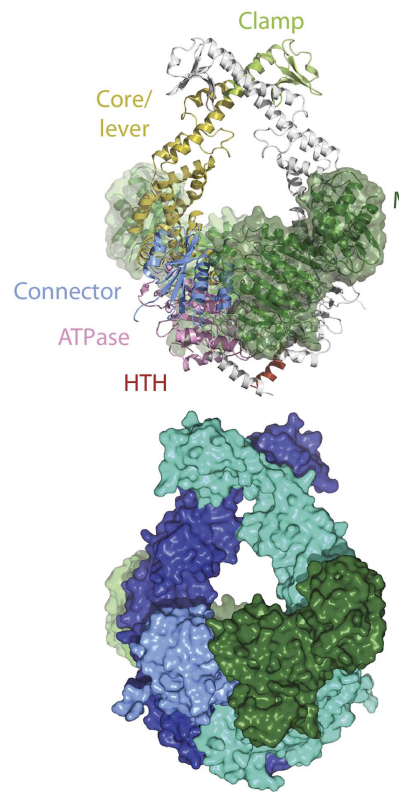

MutS $\Delta \mathrm{C} 800$ /MutL ${ }^{\mathrm{LN} 40}$ complex
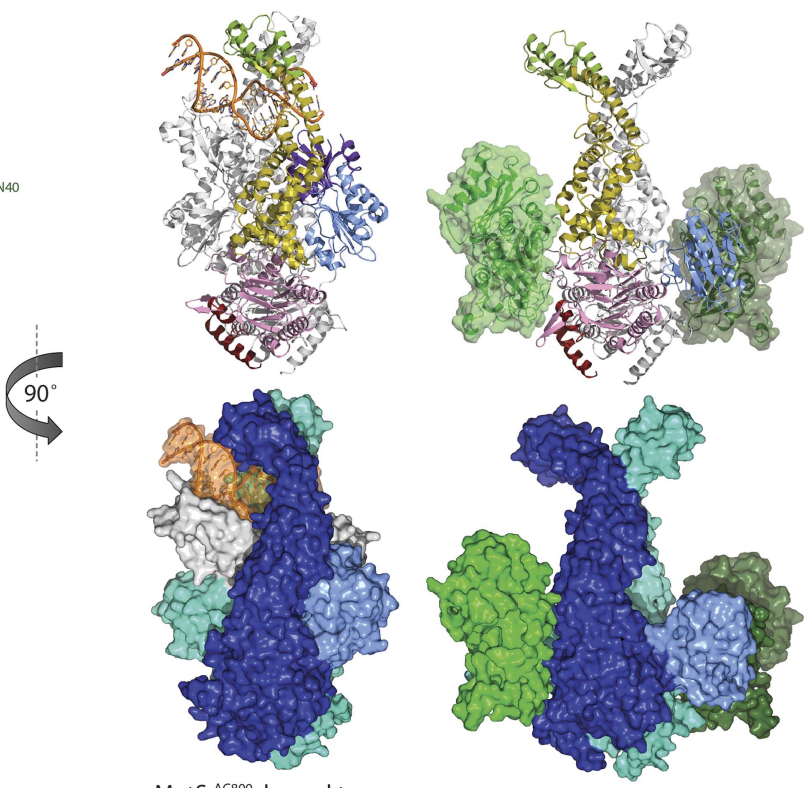

MutS $\triangle \mathrm{C} 800$ bound to mismatched DNA

MutS $\triangle \mathrm{C} 800 /$ MutL ${ }^{\mathrm{LN} 40}$ complex

D

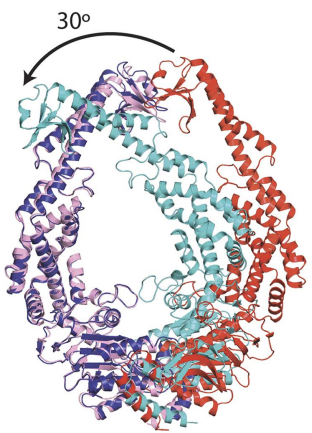

E

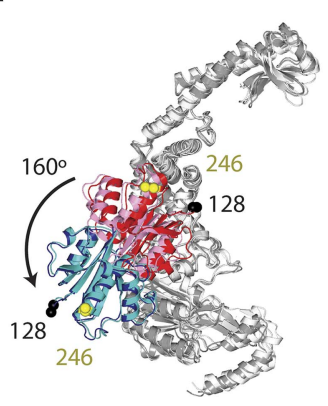

$\mathrm{F}$

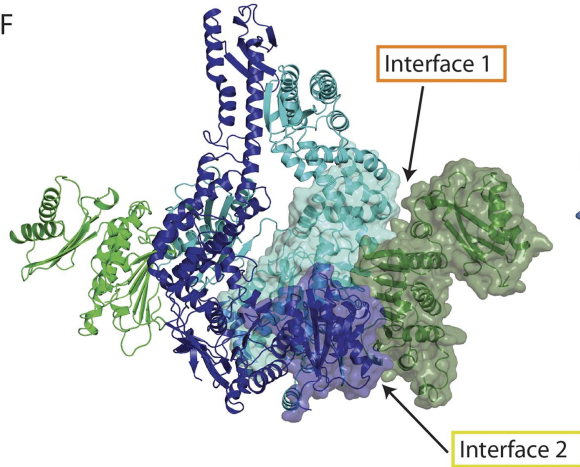

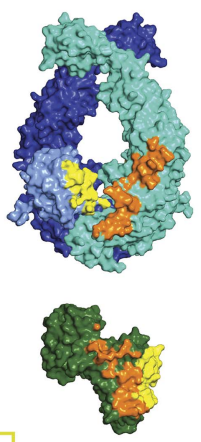

Figure 1. Crystal structure of the crosslinked MutS $S^{\Delta C 800} /$ MutL $^{L N 40}$ complex. (A) DNA and ATP-dependent crosslinking of MutS ${ }^{\Delta C 800} D 246 C$ (S) and MutL ${ }^{L N 40}$ $\mathrm{N} 131 \mathrm{C}(\mathrm{L})$ and large-scale purification. Constructs and domain definitions are shown. (B) Crystal structure of the trapped transient complex of MutS ${ }^{\Delta \mathrm{C} 800}$ dimer (blue/cyan) with MutL ${ }^{\text {LN40 }}$ (green). (C) Comparison between MutS ${ }^{\Delta C 800}$ in mismatch-recognition state (1E3M.pdb) and the MutS ${ }^{\Delta C 800 / M u t L}{ }^{L N 40}$ complex, with MutS subunit B colored as in (A). (D) The dimer subunits (blue/cyan) tilt across each other (connector and mismatch-binding domains not Figure 1. continued on next page 
Figure 1. Continued

shown for clarity) compared to the mismatch-bound state (red/pink). (E) The connector domain (blue/cyan) rotates around residues 265-266 compared to the mismatch-bound state (red/pink) relative to other domains. Reorientation of residues 128 and 246 indicated. (F) Each MutL ${ }^{\text {LN40 }}$ subunit (green) interacts via two interfaces (orange/yellow) with the MutS ${ }^{\Delta C 800}$ dimer (blue/cyan).

DOI: 10.7554/eLife.06744.003

The following figure supplements are available for figure 1:

Figure supplement 1. Crosslinking, purification and crystal structure of the $856 \mathrm{MutS}^{\Delta \mathrm{C} 800} / \mathrm{MutL}^{\mathrm{LN} 40} \mathrm{complex}$ DOI: 10.7554/eLife.06744.004

Figure supplement 2. Electron density for different crystal forms of the MutS $\mathrm{SC}^{\Delta \mathrm{C} 00} / \mathrm{MutL}^{\mathrm{LN} 40} \mathrm{complex}$. DOI: 10.7554/eLife.06744.005

The type of rearrangement of the MutS N-terminal region was similarly unexpected. In this movement the connector domains have rotated onto the so-called 'signature helix' (residues 670-684) (Hopfner and Tainer, 2003), whose amino terminus interacts with the $\gamma$-phosphate of the ATP in the opposite subunit in ABC ATPases. Therefore the observed connector domain movement could be the result of binding of ATP in the opposing subunit.

In RAD50 this tilting or 'closing' motion is transmitted through a 'signature coupling helix' via charged interactions with the signature helix (Williams et al., 2011; Deshpande et al., 2014). This 'coupling helix' is found at the beginning of a long stretch (144-767) in RAD50 that includes the coiled coil region and ends in the signature helix. The equivalent region in MutS is only 10 residues long (660-669) and it is disordered in all structures. It is feasible that this 10-residue loop is critical for transmission of the ATP signal, but the details must be different, since the basic residues in the signature helix of RAD50 are not conserved in MutS.

To validate the relevance of the observed conformational changes for the MMR process, MutS proteins with a single cysteine at position 449 were site-specifically labeled with two different Alexa fluorophores and combined into heterodimers by random subunit exchange (Figure 2A, Figure 2-figure supplement 2). When labeled protein was bound to end-blocked DNA containing a G:T mismatch, FRET increased upon ATP addition. This indicates that ATP-induced sliding clamp formation moves these residues toward each other, in line with the shorter distance in the new conformation (from $50 \AA$ in the mismatch-recognition state to $43 \AA$ in the MutL ${ }^{\mathrm{LN} 40}$-bound structure).

The new position of the connector domain brings it closer to the ATPase domain (Figure 1E, Video 1). To analyze this movement we combined two single-cysteine variants of MutS, labeled in the connector domain (residue 246) and the ATPase domain (residue 798) respectively, into heterodimers, and measured the FRET signal between these sites upon sliding clamp formation (Figure 2B, Figure 2-figure supplement 2). Indeed, after ATP addition the FRET increased, indicating that these residues come closer together. As this is measured in the absence of MutL it suggests that after mismatch binding, ATP is sufficient to induce movement of the connector domain away from the mismatch-recognition position.

Although the complex was crystallized in the presence of DNA containing a mismatch, the DNA is not visible in the structure. This could be due to smearing out of the electron density over multiple positions or the DNA may not be present in the crystal, both indicating that the mismatch has been released, as expected for the ATP-bound state of MutS.

The subunit tilting has occluded the original DNA binding site, but because the connector and mismatch-binding domains have moved, a large channel ( $35 \AA$ wide) in MutS has become accessible, which could easily accommodate a DNA duplex (20 ̊ diameter). The new channel is lined by conserved lysines and arginines (Figure 2C, Figure 2-figure supplement 1C), which can govern nonspecific contacts with the negative backbone of DNA, as expected for the MutS sliding clamp state (Cho et al., 2012). Moreover, in our crystal forms these channels are aligned between symmetry mates or even within the asymmetric unit (Figure 2-figure supplement 1B). This packing of MutS/ MutL complexes is most likely a crystallographic artefact, as it could not occur in the presence of MutL dimers, but the alignment could reflect the path of the DNA present during crystallization. We hypothesize that the DNA is pushed down to this channel during the ATP-induced conformational changes of MutS after mismatch recognition.

To test whether DNA moves down into the new channel in solution, we analyzed FRET signals between fluorescently labeled DNA (end-blocked) and specific sites in single-cysteine MutS variants 
Table 1. Data collection and refinement statistics

\begin{tabular}{|c|c|c|c|}
\hline & $\begin{array}{l}\text { Crystal form } 1 \\
\text { 27-bp DNA }\end{array}$ & $\begin{array}{l}\text { Crystal form } 2 \\
\text { 27-bp DNA }\end{array}$ & $\begin{array}{l}\text { Crystal form } 3 \\
\text { 100-bp DNA }\end{array}$ \\
\hline \multicolumn{4}{|l|}{ Data collection } \\
\hline Space group & $\mathrm{C} 2$ & $\mathrm{C} 2$ & $\mathrm{P} 2_{1}$ \\
\hline \multicolumn{4}{|l|}{ Cell dimensions } \\
\hline$a, b, c(\AA)$ & $165.9,188.5,200.4$ & $380.6,126.5,243.3$ & $192.6,109.4,277.5$ \\
\hline$\alpha, \beta, \gamma\left({ }^{\circ}\right)$ & $90.0,94.8,90.0$ & $90.0,91.4,90.0$ & $90.0,90.0,90.0$ \\
\hline Resolution $(\AA)^{\star}$ & $82.7-4.71(4.96-4.71)$ & $49.94-6.6(7.13-6.6)$ & $49.3-7.6(8.5-7.6)$ \\
\hline$R_{\text {merge }}$ & $19.4(79.7)$ & $21.3(80.1)$ & $16.8(91.9)$ \\
\hline$|/ \sigma|$ & $2.5(1.0)$ & $3.4(1.1)$ & $4.3(1.0)$ \\
\hline Completeness (\%) & $97.3(98.0)$ & $96.8(97.7)$ & $81.3(82.5)$ \\
\hline Redundancy & $2.4(2.4)$ & $2.9(3.0)$ & $2.3(2.2)$ \\
\hline \multicolumn{4}{|l|}{ Refinement } \\
\hline Resolution $(\AA)$ & 4.7 & 6.6 & 7.6 \\
\hline No. reflections & 31,052 & 21,305 & 11,763 \\
\hline$R_{\text {work/ }} R_{\text {free }}$ & $31.8 / 35.0$ & $25.6 / 28.7$ & $26.2 / 30.5$ \\
\hline No. atoms & 21,906 & 45,054 & 45,054 \\
\hline Protein & 21,813 & 44,868 & 44,868 \\
\hline Ligand/ion & 93 & 186 & 186 \\
\hline Water & 0 & 0 & 0 \\
\hline \multicolumn{4}{|l|}{ B-factors } \\
\hline Protein & 212 & 255 & 221 \\
\hline Ligand/ion & 220 & 212 & 171 \\
\hline Water & $n / a$ & $n / a$ & $n / a$ \\
\hline \multicolumn{4}{|l|}{ R.m.s deviations } \\
\hline Bond lengths $(\AA)$ & 0.009 & 0.0103 & 0.0113 \\
\hline r.m.s. Z (bonds) & 0.45 & 0.51 & 0.55 \\
\hline Bond angles $\left({ }^{\circ}\right)$ & 1.32 & 1.35 & 1.31 \\
\hline r.m.s. Z (angles) & 0.59 & 0.70 & 0.68 \\
\hline
\end{tabular}

*Highest resolution shell is shown in parenthesis.

DOI: 10.7554/eLife.06744.019

(Figure 2D). After addition of ATP, DNA moves away from residues 449 at the DNA-clamp position (FRET/acceptor ratio reduction $\sim 1.5$ fold), while an increase in FRET/acceptor ratio ( $>3.6$ fold) was observed when MutS was labeled at position 336. Since the connector domain moves down itself, no substantial change in FRET/acceptor ratio is observed between residue 246 and DNA (Figure 2-figure supplement 1D, Figure 2-figure supplement 2). Combined, these FRET data are in agreement with repositioning of the DNA towards the channel created by the new conformation.

Based on these validations, we conclude that the observed MutS conformation in our crystal structure is induced by ATP after mismatch recognition. Since the new position of the DNA would allow MutS to fit as a loose ring around the DNA duplex (with a channel size similar to that of PCNA (Krishna et al., 1994)), consistent with free movement over DNA (Cho et al., 2012), we propose that this is the MutS sliding clamp conformation.

\section{Orientation of MutL ${ }^{\mathrm{LN} 40}$ on MutS}

In the structure MutL ${ }^{\mathrm{LN} 40}$ makes two interfaces with MutS ${ }^{\Delta \mathrm{C} 800}$. Interface 1 orients MutL ${ }^{\mathrm{LN} 40}$ on the ATPase and core domains of MutS. Recently, a loop in Bacillus subtilis MutS was found to be essential for MutL interaction (Lenhart et al., 2013). Although the equivalent loop is shorter in E. coli MutS and 


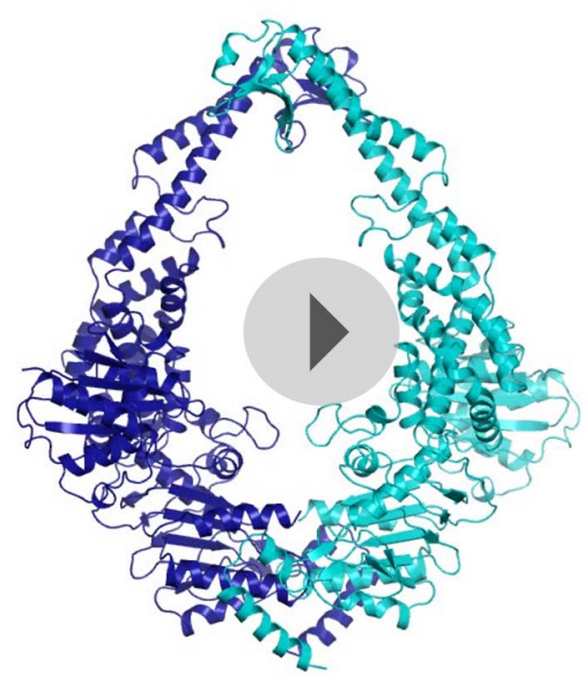

Video 1. Interpolation between two MutS conformations. Interpolation between the mismatch-bound conformation of MutS and the conformation as observed in complex with MutL LN40 shows tilting of the MutS subunits across each other. The connector domain rotates outward, although the exact trajectory may be different than in this visualization. Mismatch-recognition domains are not shown since they are not visible in the MutS ${ }^{\Delta \mathrm{C} 800} / \mathrm{MutL}^{\mathrm{LN} 40}$ structure.

DOI: 10.7554/eLife.06744.009 the explicit residues (F319/F320) are missing, the corresponding region is located within the $\sim 590 \AA^{2}$ interface (interface 1 ) with MutL ${ }^{\text {LN40 }}$.

We validated the observed interaction at interface 1 by a crosslinking experiment with a short crosslinker. We created single-cysteine mutants MutS ${ }^{\Delta \mathrm{C} 800} \mathrm{~A} 336 \mathrm{C}$ and MutL ${ }^{\mathrm{LN} 40}$ T218C (Figure 3A), which are located $\sim 7.4 \AA$ apart in the structure, and then showed that we could crosslink them efficiently with a short cysteinespecific crosslinker (8 $\AA$, BMOE), dependent on the presence of both mismatched DNA and ATP (Winkler et alo, 2011). Only background crosslinking occurred when using MutS ${ }^{\Delta C 800}$ D246C (connector domain) with MutL ${ }^{\text {LN40 }}$ T218C (interface 1) under these conditions (Figure 3-figure supplement $1 \mathrm{~A})$, indicating that the crosslinking between MutS ${ }^{\Delta \mathrm{C} 800} \mathrm{~A} 336 \mathrm{C}$ and MutL ${ }^{\mathrm{LN} 40} \mathrm{~T} 218 \mathrm{C}$ is specific.

To further verify interface 1 between MutS and MutL, we tested whether mutations in the interface affected MMR activity in vivo, in a complementation assay with MutS or MutL deficient cells (Figure 3B,F, Table 2). We found several mutants of MutL (A138E, A138E/H139A, R55D/R57D, or combinations) and a triple mutant in MutS (P595A/I597A/M759D) that could not complement loss of wild type (WT) protein. We purified the mutants that impaired MMR and characterized their defects. The MutS triple mutant has a slight defect in ATPase activity but this does not impair its sliding clamp formation (Figure 3-figure supplement 1B,C), and other mutants with similar ATPase effects (e.g. MutS F596A) can almost fully reconstitute MMR (Junop et al., 2003), suggesting that the in vivo effect we observe is due to the perturbed interface with MutL.

To assess the effect of these mutations on binding of MutL to the transient MutS sliding clamp we designed a two-stage assay using Surface Plasmon Resonance (SPR). We first formed and trapped MutS sliding clamps on 100-bp end-blocked DNA in the presence of ATP (Groothuizen et al., 2013). Next, MutL was injected, which could then bind to these MutS clamps. By subtraction of the MutS signal, the contribution of MutL could be evaluated for the different mutants (Figure 3C), since MutL alone shows no DNA binding under these conditions (Figure 3-figure supplement 1D). Indeed the interface 1 mutants that were deficient for MMR conferred a deficiency in MutS/MutL complex formation (Figure 3D).

\section{MutS sliding clamp recognition by MutL}

The rearrangement of the connector domain creates a second interface with MutL ${ }^{\text {LN40 }}$ (interface 2, Figure 3E). Previous deuterium exchange experiments (Mendillo et al., 2009) indicated that the connector domain interacts with MutL, particularly via MutS glutamines 211 and 212. Indeed in our structure these residues are buried within this $\sim 670 \AA^{2}$ interface with MutL ${ }^{\text {LN40 }}$ (Figure 3F). Interestingly, the deuterium exchange experiments identified a second region on the MutS surface that was protected upon MutL interaction in the ATPase domain (residues 673-686). These residues are located in the 'signature helix' of MutS (Hopfner and Tainer, 2003) and in the complex structure this region is masked by the MutS $\mathrm{S}^{\Delta \mathrm{C} 800}$ connector domain in its new position (Figure 3-figure supplement 1E).

ATP binding is sufficient to displace the connector domain (Figure 2B), and MutL ${ }^{\text {LN40 }}$ interaction may stabilize the position of the connector domain that we see in the crystal structure. At the resolution of our structure, there is no clear electron density for the connecting crosslinker that we 
A
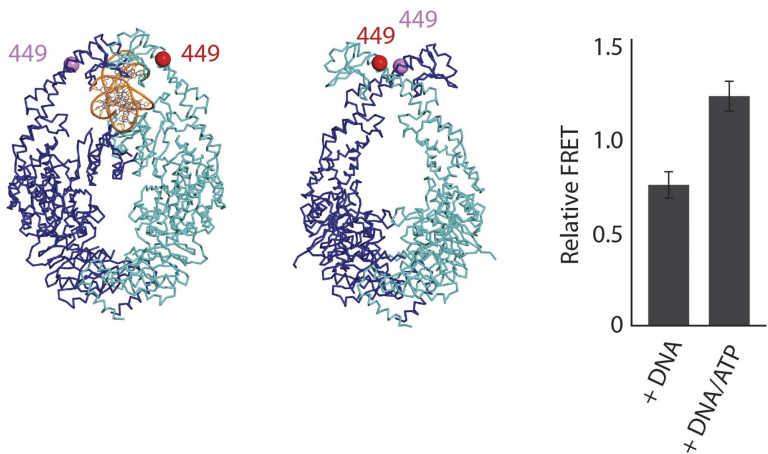

B
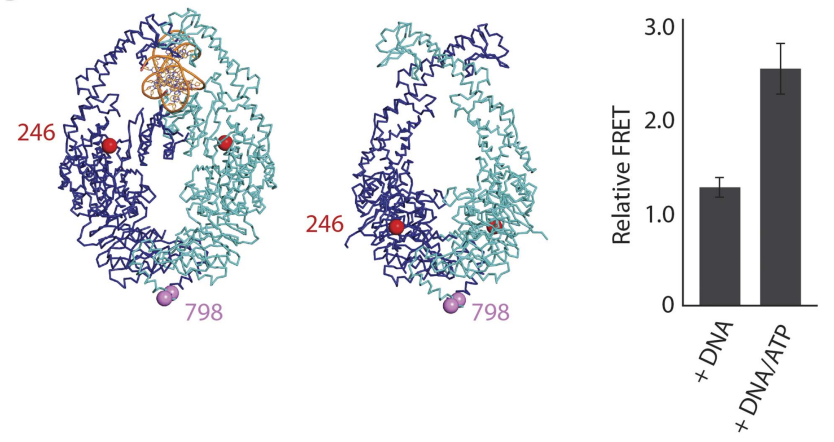

C
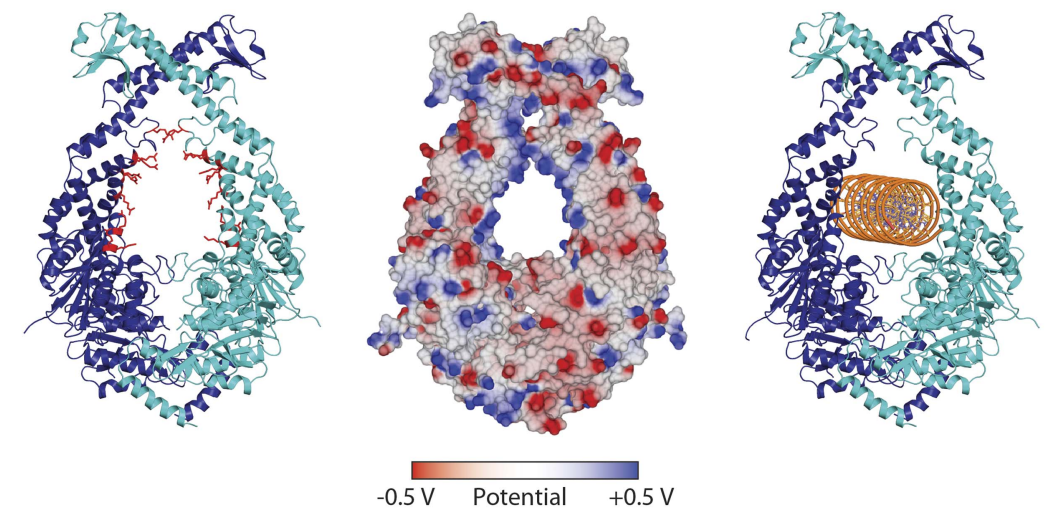

$-0.5 \mathrm{~V}$ Potential $+0.5 \mathrm{~V}$

D
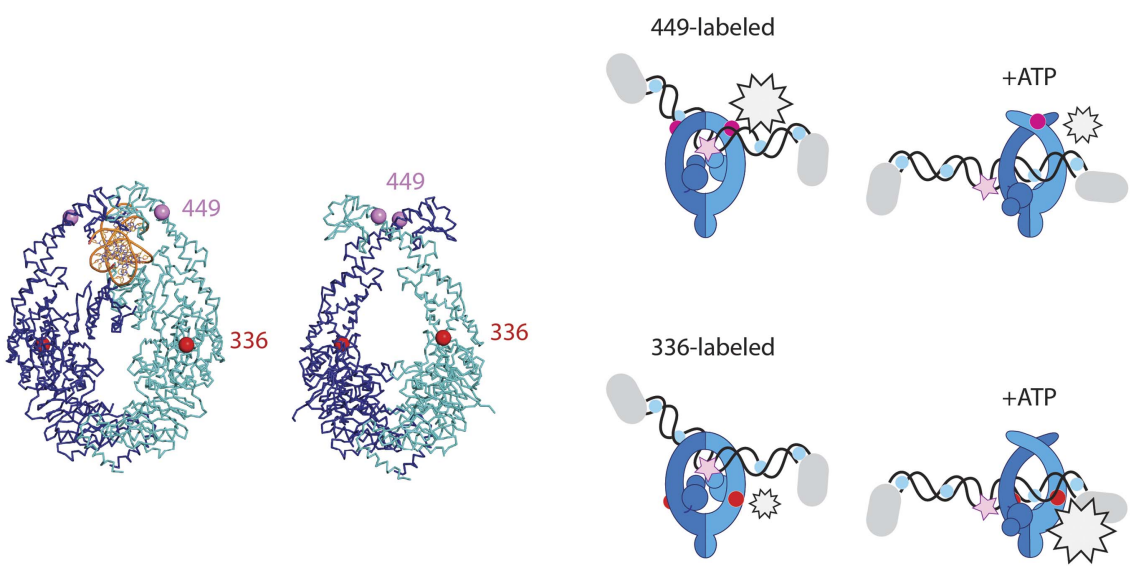
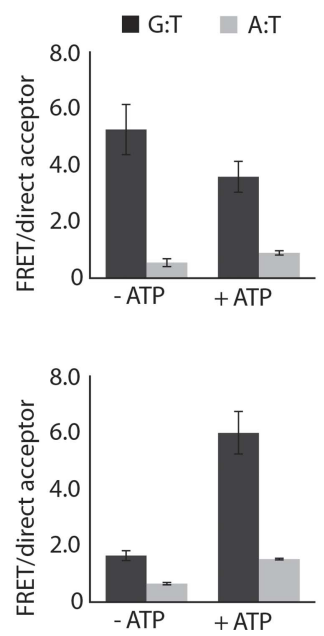

Figure 2. The structure of the MutS ${ }^{\Delta C 800} /$ MutL $^{L N 40}$ complex reveals the MutS sliding clamp conformation. (A) FRET within MutS dimers (normalized for unbound protein) reveals residues 449 coming closer together upon ATP addition. Error bars depict mean $\pm S D, n=3$. (B) FRET assay agrees with residue 246 on the connector domain of MutS moving towards residue 798 upon ATP addition after mismatch recognition. (C) Mismatch and ATP-induced conformational changes open a channel lined by positively charged residues (left: arginines and lysines as red sticks, middle: electrostatic surface), which would fit a DNA helix (right). (D) FRET assay agrees with movement of DNA away from residues 449 in MutS, while approaching residues 336 upon ATP addition as schematically depicted (DNA mismatch represented by pink star).

DOI: 10.7554/eLife.06744.006

The following figure supplements are available for figure 2:

Figure supplement 1. ATP-analog and DNA in the crystal structure.

DOI: 10.7554/eLife.06744.007

Figure supplement 2. FRET assay - controls and raw data.

DOI: 10.7554/eLife.06744.008 
A

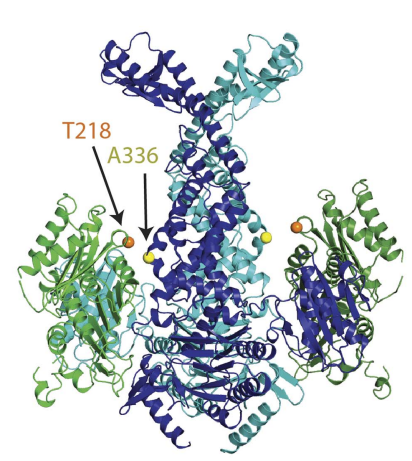

C
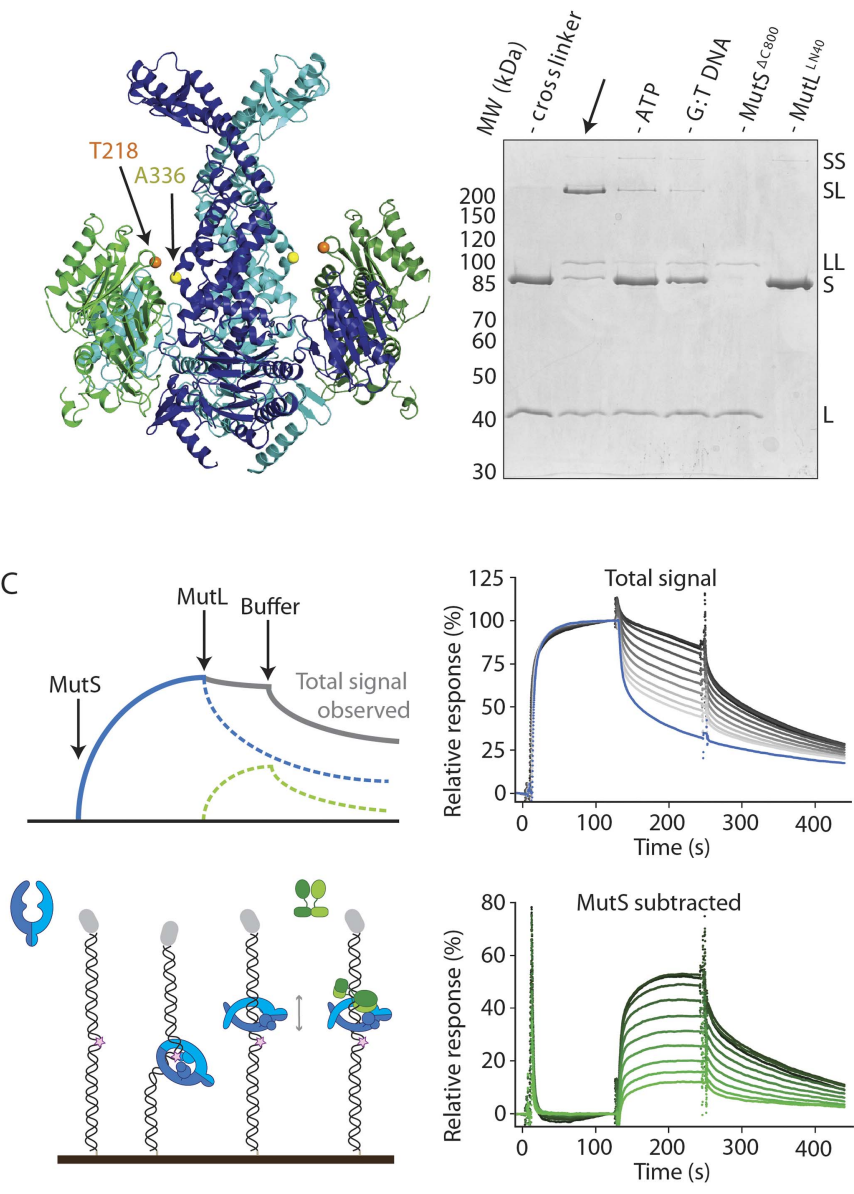

$\mathrm{E}$

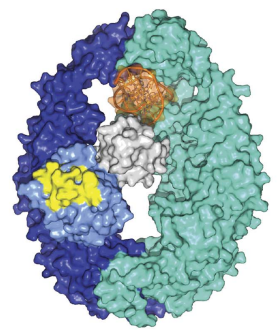

MutS $\triangle 4800$ bound to mismatched DNA

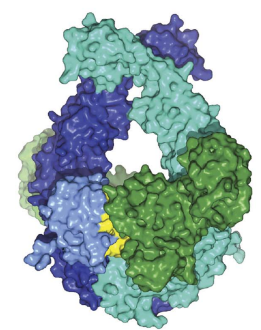

MutS $\triangle 8800 /$ MutL ${ }^{\text {LN40 }}$

complex
$\mathrm{F}$
B

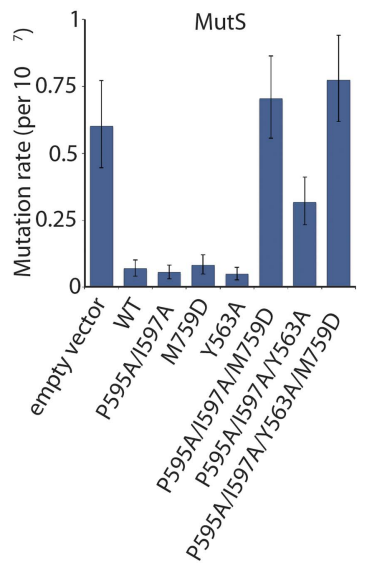

D
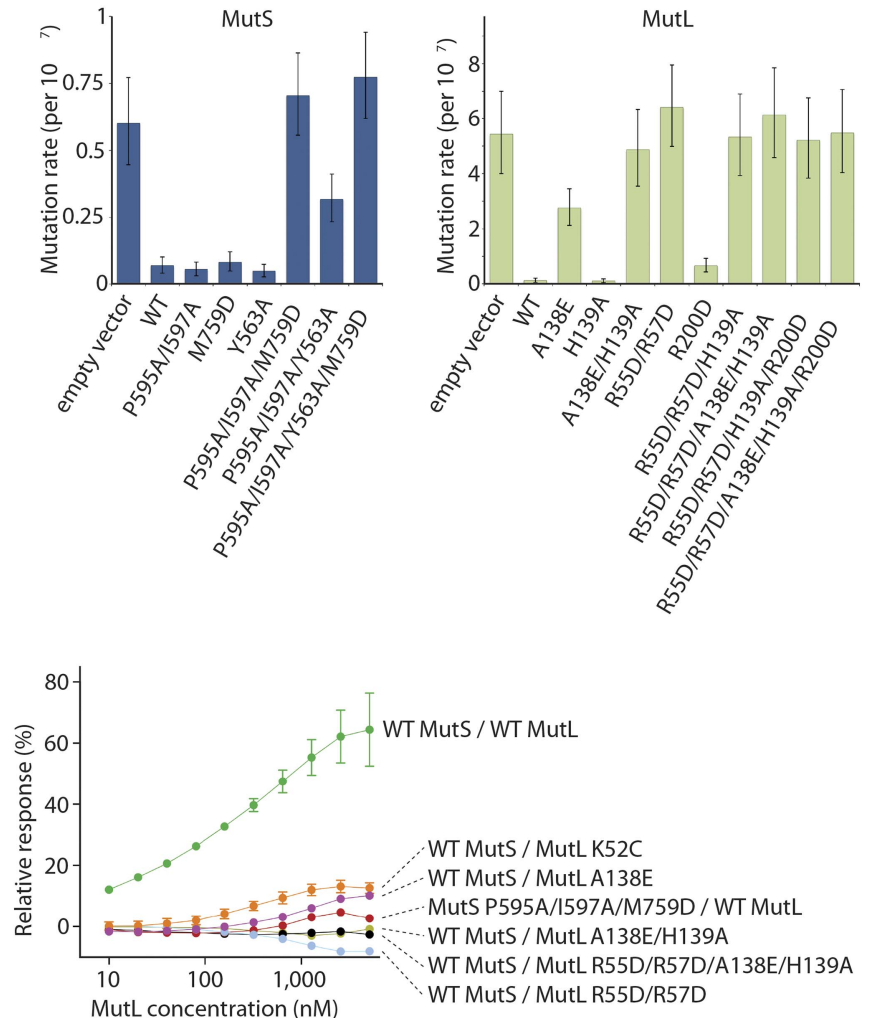
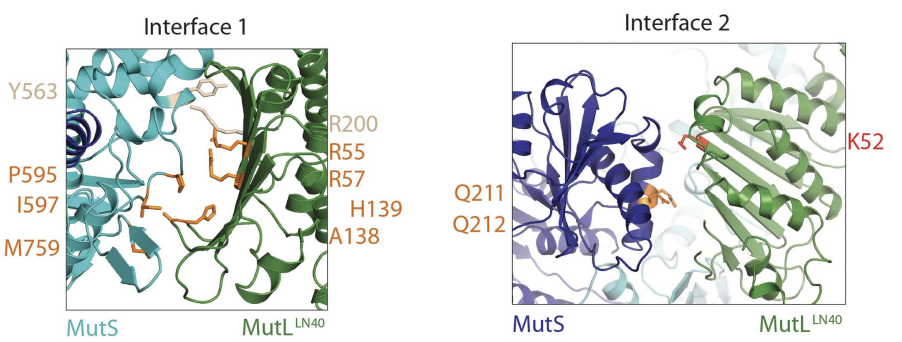

Figure 3. Interaction of the MutS $\mathrm{SC}^{\Delta \mathrm{C} 80}$ sliding clamp with MutL ${ }^{\mathrm{LN} 40}$. (A) Crosslinking occurs between MutS ${ }^{\Delta \mathrm{C} 800} \mathrm{~A} 336 \mathrm{C}$ and MutL $\mathrm{LN}^{\mathrm{LN0}} \mathrm{T} 218 \mathrm{C}$ using BMOE (right panel), as suggested by the structure (left panel). (B) Spontaneous mutation rates after complementing MutS or MutL-deficient cells with the indicated mutants. Error bars represent 95\% confidence intervals. (C) SPR assay to measure MutL binding to pre-formed MutS sliding clamps on endblocked DNA. MutL contribution (green dotted line) is approached by subtracting MutS-only contribution (blue line) from the total signal (solid line). Data normalized to maximum MutS response. (D) MutL and MutS mutants with deficiency in MMR show reduced MutS/MutL complex formation in SPR. Error bars represent SD for averages between two experiments. (E) The yellow patch of MutS ${ }^{\Delta C 800}$ interacts with MutL ${ }^{\text {LN40 }}$ in the new conformation after rearrangement of the connector domain. (F) Residues in MutS ${ }^{\Delta C 800 / M u t L}{ }^{L N 40}$ interfaces. Red: full MMR deficiency upon mutation; orange: deficiency upon combination; white: mild effect.

DOI: 10.7554/eLife.06744.010

The following figure supplements are available for figure 3:

Figure supplement 1. MutS-MutL interaction.

DOI: 10.7554/eLife.06744.011

Figure supplement 2. (A) MutL ${ }^{\mathrm{LN} 40}(\mathrm{~L})$ coelutes with crosslinked MutS $\mathrm{S}^{\Delta \mathrm{C} 800} / \mathrm{MutL}^{\mathrm{LN} 40}$ complex (SL) from size-exclusion chromatography (right), after incubation with 100-bp DNA with a G:T mismatch and AMP-PNP, indicating that MutL can still dimerize in this complex.

DOI: 10.7554/eLife.06744.012 
Biophysics and structural biology | Genes and chromosomes

Table 2. Mutation rates for MutS and MutL mutants as determined using in vivo complementation assays

Protein

MutS variant (MutL interface)

\begin{tabular}{|c|c|c|}
\hline Empty vector & 0.601 & $(0.446-0.772)$ \\
\hline WT MutS & 0.0686 & $(0.0408-0.101)$ \\
\hline MutS P595A/I597A & 0.0545 & $(0.0310-0.0826)$ \\
\hline MutS M759D & 0.0819 & $(0.0490-0.121)$ \\
\hline MutS Y563A & 0.0488 & $(0.0272-0.0749)$ \\
\hline MutS P595A/I597A/M759D & 0.704 & $(0.556-0.864)$ \\
\hline MutS Y563A/P595A/I597A & 0.317 & $(0.233-0.411)$ \\
\hline MutS Y563A/P595A/I597A/M759D & 0.773 & $(0.618-0.941)$ \\
\hline \multicolumn{3}{|l|}{ MutL variant (MutS interface) } \\
\hline Empty vector & 5.43 & $(4.00-7.00)$ \\
\hline WT His-MutL & 0.121 & $(0.0542-0.206)$ \\
\hline His-MutL A138E & 2.76 & $(2.12-3.46)$ \\
\hline His-MutL H139A & 0.103 & $(0.0439-0.179)$ \\
\hline His-MutL A138E/H139A & 4.87 & (3.55-6.33) \\
\hline His-MutL R55D/R57D & 6.41 & $(4.99-7.95)$ \\
\hline His-MutL R200D & 0.663 & $(0.432-0.932)$ \\
\hline His-MutL R55D/R57D/H139A & 5.33 & $(3.93-6.89)$ \\
\hline His-MutL R55D/R57D/A138E/H139A & 6.13 & $(4.58-7.84)$ \\
\hline His-MutL R55D/R57D/H139A/R200D & 5.22 & $(3.84-6.76)$ \\
\hline $\begin{array}{l}\text { His-MutL R55D/R57D/A138E/H139A/ } \\
\text { R200D }\end{array}$ & 5.48 & $(4.04-7.06)$ \\
\hline \multicolumn{3}{|l|}{ MutL variant (DNA binding) } \\
\hline His-MutL R266E & 5.87 & $(4.78-7.04)$ \\
\hline His-MutL R162E/R266E/R316E & 5.39 & $(4.37-6.49)$ \\
\hline
\end{tabular}

Mutation rates and 95\% confidence intervals were determined using the Fluctuation AnaLysis CalculatOR (http://www.mitochondria.org/protocols/FALCOR.html) using the MSS-MLE method. For MutS, at least 24 independent colonies were picked; for MutL at least 12 independent colonies were picked.

DOI: $10.7554 /$ eLife. 06744.013

used to stabilize the complex, and the crosslinked residue $131 \mathrm{C}$ on MutL ${ }^{\mathrm{LN} 40}$ could not be modeled. However, the distance between $\mathrm{C} \alpha$ atoms of crosslinked residue $246 \mathrm{C}$ in MutS $\mathrm{S}^{\Delta \mathrm{C} 800}$ and residue 132 in MutL ${ }^{L N 40}$ is shorter $(\sim 15.5 \AA)$ than the $18 \AA$ crosslinker (further spaced by cysteine side-chains), showing that the crosslinker can not enforce the observed position of the connector domain.

On the MutL side of interface 2, residue K52 of MutL ${ }^{\mathrm{LN} 40}$ is involved in the interaction with the connector domain of MutS ${ }^{\Delta C 800}$ (Figure 3F). This explains the previously reported unexpected mutator phenotype of MutL K52C (Giron-Monzon et al., 2004). To confirm its role in the interface we measured the binding of MutL K52C to the MutS sliding clamp in our SPR assay (Figure 3D). Indeed, the binding of this mutant is reduced compared to WT MutL.

The ATP-induced tilting of the subunits within MutS and the accompanying connector domain movement positions interfaces 1 and 2 such that they become simultaneously available for binding to the N-terminal domain of MutL (Figure 1F). Perturbing either interface 1 or interface 2 impairs MutL binding and MMR (Figure 3F). This explains the specificity of MutL for the MutS sliding clamp, which has never been understood before.

MutL proteins dimerize through the C-terminal LC20 domains. The LN40 domains are monomeric in isolation, but can form unstable dimers after ADP or ATP binding or stable dimers when incubated with AMP-PNP (Ban and Yang, 1998; Ban et al., 1999). Our crosslinked protein crystallizes as MutS ${ }^{\Delta C 800}$ dimers bound to MutL ${ }^{\mathrm{LN} 40}$ monomers, and does not show the MutL ${ }^{\mathrm{LN} 40}$ dimer arrangement 
through crystal contacts. Accordingly the MutL monomers have the apo-conformation of residues 80-103 (Ban and Yang, 1998) and no density for a nucleotide is visible. However, the interfaces with MutS sterically allow MutL dimerization (Figure 3-figure supplement 1F), and in analytical gel filtration, MutL ${ }^{L N 40}$ coelutes with the $\mathrm{S}_{2} / \mathrm{L}_{2}$ complex after incubation with DNA and AMP-PNP (Figure 3-figure supplement 2A).

The stoichiometry of the MutS/MutL complex in vivo is a topic of interest (Hombauer et alo, 2011; Elez et al., 2012). To obtain crystallizable complexes, MutL ${ }^{\mathrm{LN} 40}$ was bound to each MutS ${ }^{\Delta C 800}$ subunit in our experiments, but during MMR a symmetric complex may not be necessary. Indeed the asymmetry of the eukaryotic MMR proteins suggest that this is not required and that a single heterodimeric MutL $\alpha$ will bind to one MSH2/MSH6 or MSH2/MSH3 heterodimer. Literature suggests that interface 2 will be made with MSH2 (Mendillo et alo, 2009), implying that interface 1 will be with MSH6. The observed MutL ${ }^{\mathrm{LN} 40}$ protein would then correlate with the MLH1 subunit (Plotz et al., 2003) (Figure 3-figure supplement 2B).

\section{Binding to MutS positions MutL on DNA}

MutL and homologs have weak DNA binding ability (Bende and Grafström, 1991; Ban et al., 1999; Hall et al., 2001; Plotz et al., 2003) which is only clearly observed in low salt conditions, and retention of MutS on DNA upon MutL interaction has been observed (Drotschmann et al., 1998; Schofield et al., 2001). Although different from the proposed DNA orientation in the crystal (Figure 2-figure supplement 1B), a model can be constructed in which the DNA running through the channel in the MutS sliding clamp is simultaneously bound by the proposed DNA binding grooves of the MutL ${ }^{\mathrm{LN} 40}$ subunits (Schorzman et al., 2011) (Figure 4A, Figure 4-figure supplement 1A). While such DNA binding may require additional conformational changes of MutL, it suggests a mechanism where MutS loads MutL onto DNA.

We tested for MutL ${ }^{\text {LN40 }}$ loading onto DNA in the context of the MutS/MutL complex in an SPR assay, comparing MutS ${ }^{\Delta C 800}$ alone with MutS ${ }^{\Delta C 800}$ crosslinked to MutL ${ }^{L N 40}$ when it is flowed over 100-bp DNA with a G:T mismatch in the presence of ATP (Figure 4B). MutS $\mathrm{S}^{\Delta \mathrm{C} 800}$ alone displays fast release from the DNA due to ATP-dependent sliding-clamp formation (Groothuizen et alo, 2013), as shown by the effect of blocking the end of the DNA (Figure 4-figure supplement 1E). The presence of crosslinked MutL ${ }^{\mathrm{LN} 40}$ greatly reduces the rate of release, suggesting additional DNA binding. The

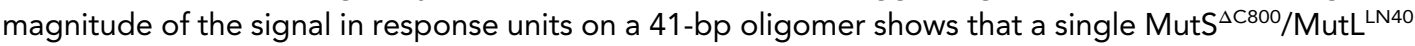
complex is sufficient for this effect (Figure 4-figure supplement 1B,C). This delay in release from DNA is also observed when using a mixture of WT MutL and MutS ${ }^{\Delta C 800}$, although to a lesser extent (Figure 4-figure supplement 1D). The remaining slow release of the crosslinked complex is not affected by blocking of the free DNA end by antibody (Figure 4-figure supplement 1E) indicating that the constitutive interaction with crosslinked MutL ${ }^{\mathrm{LN} 40}$ completely stops MutS ${ }^{\Delta \mathrm{C} 800}$ dissociation from DNA ends.

To validate that the slower release from DNA is indeed due to MutL ${ }^{\operatorname{LN} 40}$ binding to DNA, we made point mutants of the MutL ${ }^{\mathrm{LN} 40}$ protein and crosslinked them to MutS. Mutation R266E reduces DNA binding by MutL (Junop et alo, 2003; Robertson et al., 2006) (Figure 4B), most pronounced in fulllength context. This mutation also reduces the ability of crosslinked MutL ${ }^{L N 40}$ to retain the MutS ${ }^{\Delta C 800}$ sliding clamp on DNA (Figure 4D, Figure 4-figure supplement 1B,F). When introducing two additional mutations (R162E and R316E) in the MutL ${ }^{\mathrm{LN} 40}$ DNA binding site as suggested by the crystal structure (Figure 4A), DNA binding is completely abolished (Figure 4C) and the MutS ${ }^{\triangle \mathrm{C} 800} /$ MutL $^{\text {LN40 }}$ complex releases as fast as MutS ${ }^{\Delta C 800}$ alone (Figure 4D, Figure 4-figure supplement 1B,F). This indicates that MutL binds DNA when interacting with the MutS sliding clamp.

\section{MutL is loaded onto DNA after MutS releases the mismatch, which is essential in MMR}

To assess whether the loading of MutL ${ }^{\text {LN40 }}$ onto DNA is kinetically distinct from MutS mismatch recognition, we set up an assay to separate events. We read out mismatch recognition (Lamers et al., 2000; Obmolova et al., 2000; Warren et al., 2007) by the kinking of DNA, which can be assessed using 45-bp heteroduplex DNA labeled with Alexa fluorophores on each side of the mismatch (Cristóvão et al., 2012), Figure 5A, Figure 5-figure supplement 1A), in a stopped-flow set up. In parallel we follow DNA interaction using fluorescence polarization (FP) of TAMRA-labeled DNA 


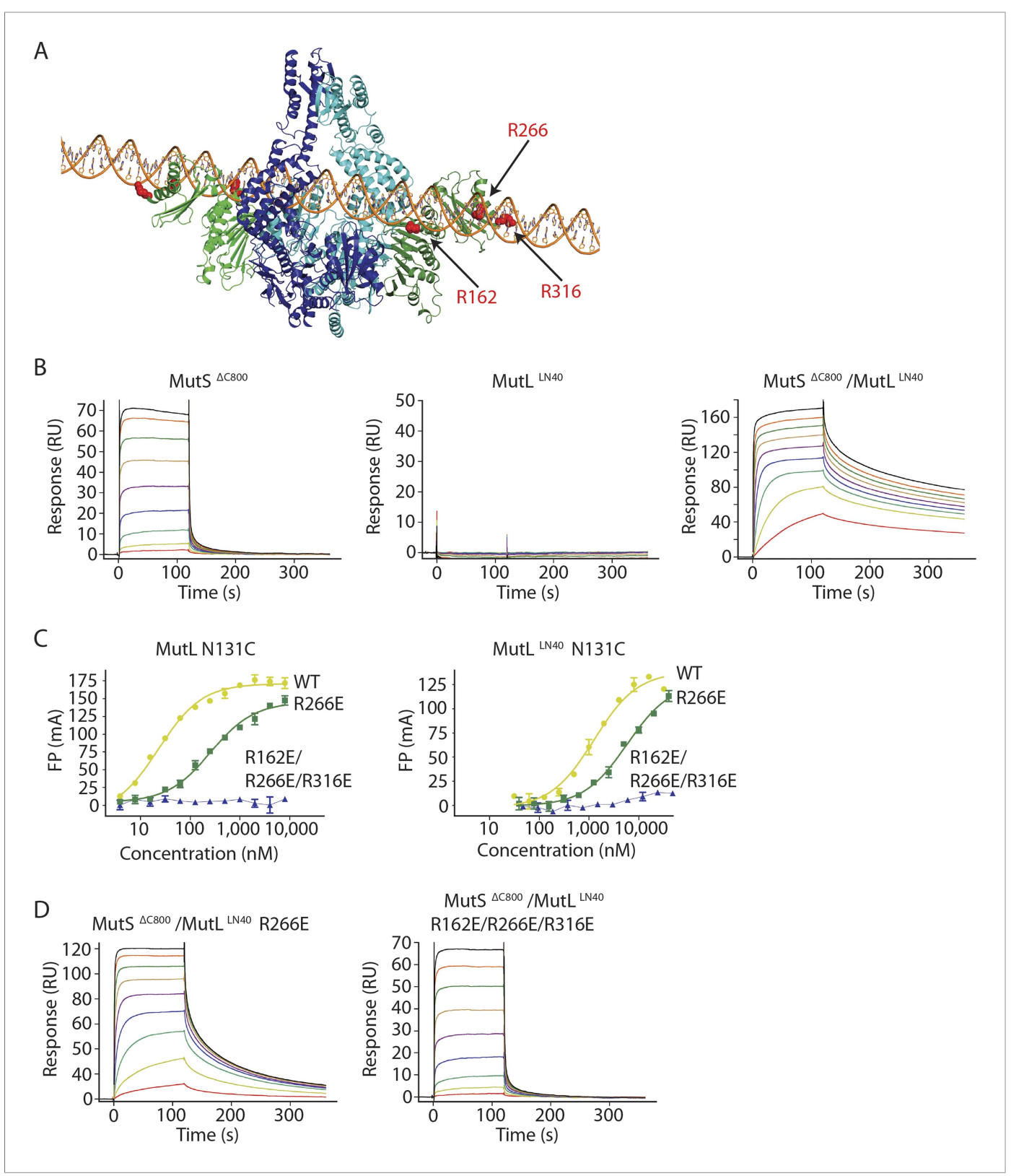

Figure 4. The MutS sliding clamp positions MutL onto DNA. (A) Model of DNA binding by the MutS $\mathrm{CC}^{\mathrm{C} 800} / \mathrm{MutL}^{\mathrm{LN40}}$ complex. Three arginines in the MutL ${ }^{\mathrm{LN} 40}$ DNA-binding groove are shown as red spheres. (B) In the presence of ATP, MutS ${ }^{\triangle \mathrm{C} 800}$ has a fast off-rate from 100-bp DNA and MutL ${ }^{\mathrm{LN} 40}$ alone does not bind DNA under physiological salt $(150 \mathrm{mM} \mathrm{KCl})$, while the crosslinked MutS ${ }^{\Delta C 800} /$ MutL $^{\mathrm{LN} 40}$ complex releases slowly from DNA. (C,D) Mutations in the DNA-binding groove of MutL reduce its DNA-binding ability (observed in low salt, $50 \mathrm{mM} \mathrm{KCl}$ ) (C) and affect release rates of the MutS $\mathrm{SC}^{\Delta \mathrm{C} 00} / \mathrm{MutL}^{\mathrm{LN} 40}$ complex in physiological salt conditions (D).

DOI: 10.7554/eLife.06744.014

The following figure supplement is available for figure 4 :

Figure supplement 1. DNA binding by the MutS ${ }^{\Delta \mathrm{C} 800} / \mathrm{MutL}^{\mathrm{LN40}}$ complex. DOI: 10.7554/eLife.06744.015

with the same sequence. This shows that the kinking is concurrent with DNA binding by MutS ${ }^{\Delta \mathrm{C} 800}$, while kinking is not observed when homoduplex is used (Figure 5A, Figure 5-figure supplement 1A). When the assay is performed in the presence of ATP, MutS ${ }^{\Delta C 800}$ binds and kinks the DNA but subsequently releases due to sliding clamp formation, after which an equilibrium is reached between rebinding and release (Figure 5B, Figure 5-figure supplement 1B). 
A

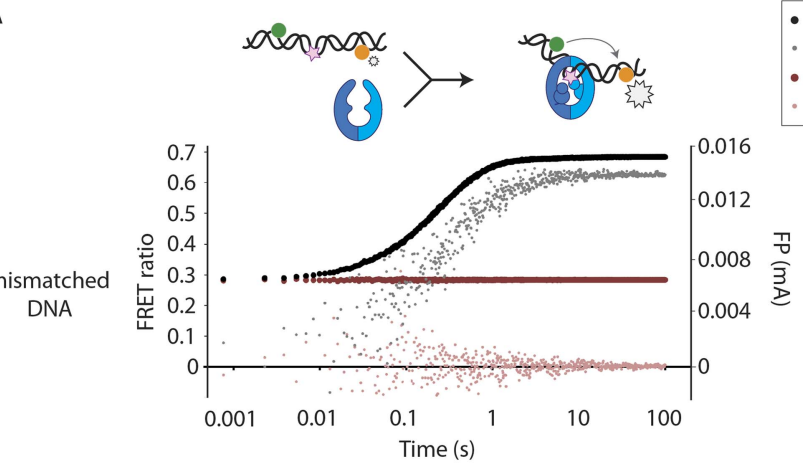

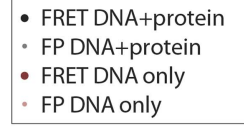

FRET DNA only homoduplex

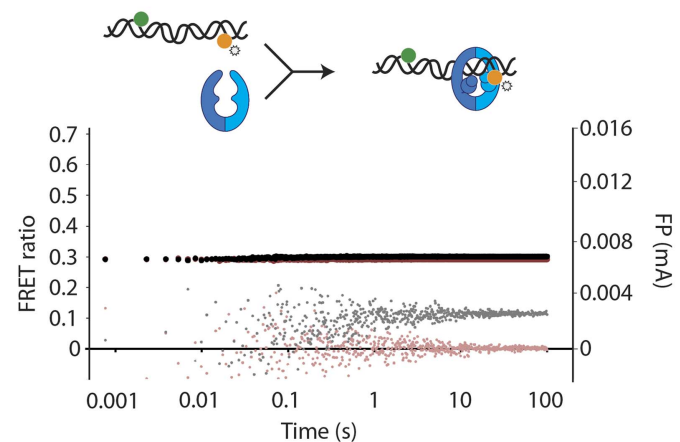

B
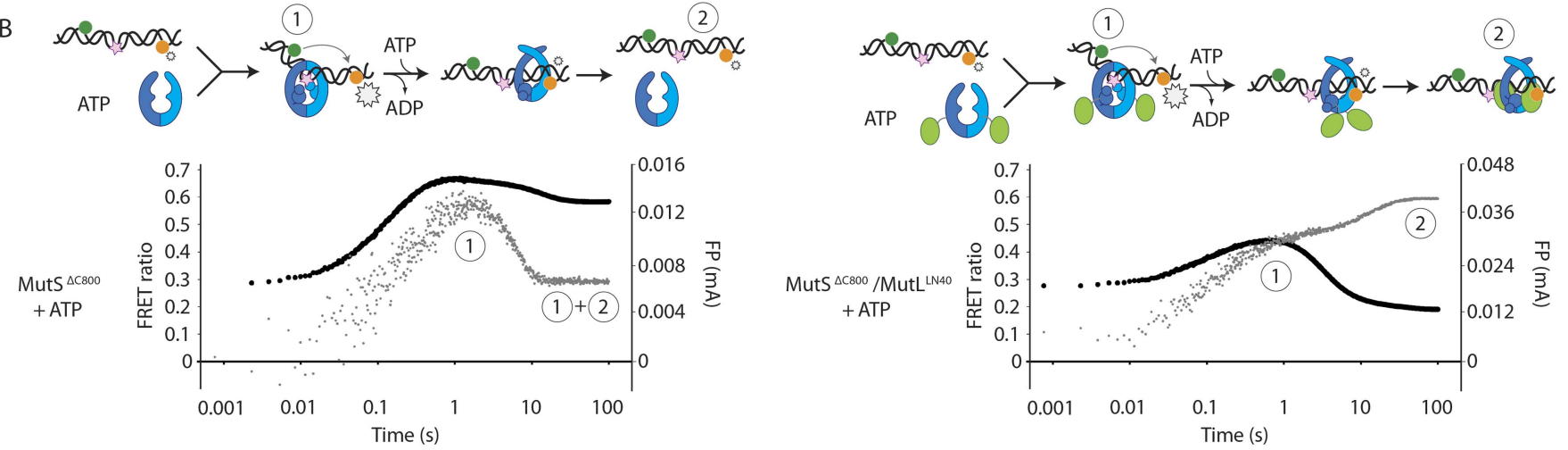

C

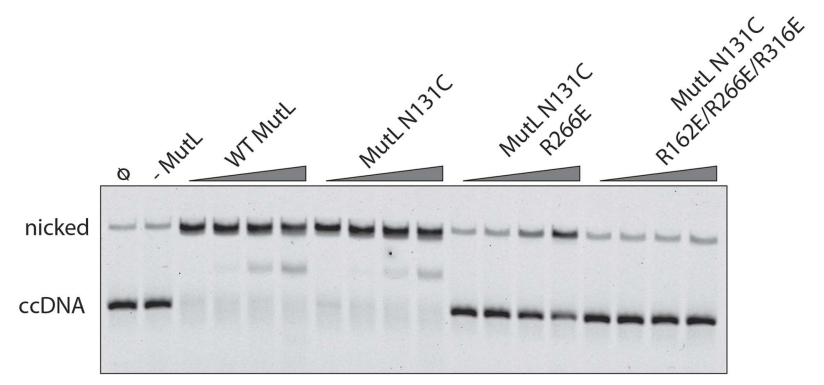

E

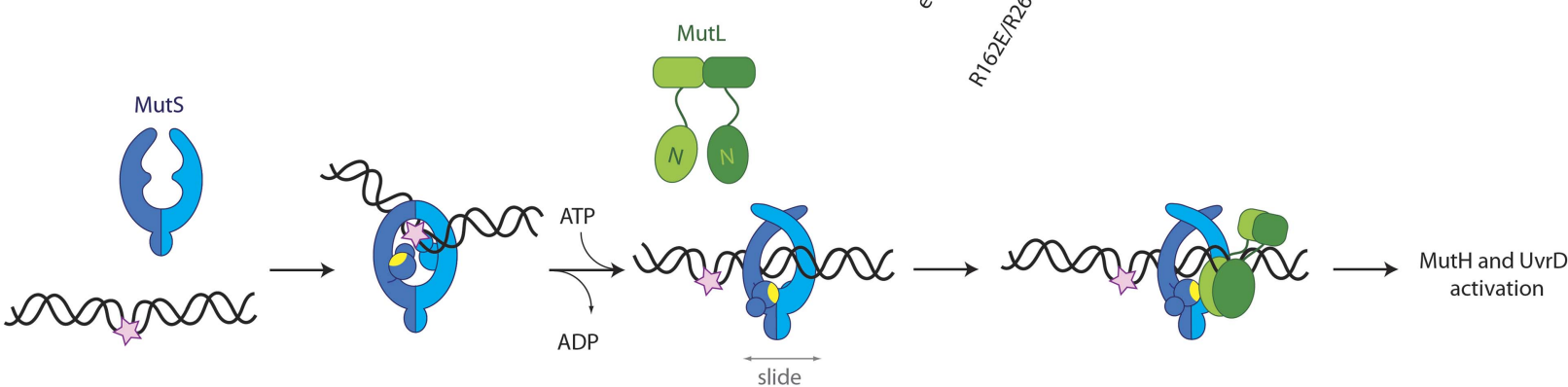

Figure 5. Implications for DNA mismatch repair initiation. (A) Stopped-flow FRET and FP assay shows kinking of 45-bp DNA by MutS ${ }^{\Delta C 800}$ binding only if there is a mismatch. Magnitude of FRET events are indicated by stars in the cartoon. (B) While MutS ${ }^{\Delta C 800}$ initially kinks the DNA and subsequently releases in the presence of ATP, the MutS ${ }^{\Delta C 800} / M_{\text {MutL }}^{\text {LN40 }}$ shows a secondary FP event without kinking the DNA. (C) Nicking assay of mismatch containing closed circular DNA (ccDNA) shows that WT or single-cysteine MutL can activate MutH, while mutations in the DNA-binding groove of MutL strongly impair the activation. (D) Spontaneous mutation rates after complementing MutL-deficient cells shows that the DNA-binding ability of MutL is essential for MMR in vivo. Error bars represent 95\% confidence intervals. (E) Model for MMR initiation. After MutS undergoes an ATP-induced conformational change to allow binding of both subunits to one MutL molecule, MutL N-termini can interact and possibly dimerize, to be loaded onto DNA where MutL can activate downstream effectors.

DOI: 10.7554/eLife.06744.016

Figure 5. continued on next page 
Figure 5. Continued

The following figure supplement is available for figure 5:

Figure supplement 1. DNA kinking by MutS $\mathrm{S}^{\Delta \mathrm{C} 800}$ and MutS $\mathrm{SCB00}_{\mathrm{Mut}}^{\mathrm{LN40}}$.

In the presence of the crosslinked complex we observed a two-step sequence of events (Figure 5B). The first increase in FP is consistent with mismatch recognition by MutS ${ }^{\Delta \mathrm{C} 800}$, simultaneous with an increase in FRET due to kinking of the DNA. A second event increases FP even more but reduces the FRET signal to below starting value (Figure 5-figure supplement 1B). This can be explained by release of the mismatch (unkinking) and sliding clamp formation. Now, however, the complex does not slide off the DNA but instead the MutL ${ }^{\mathrm{LN} 40}$ is docked onto the DNA to keep the complex bound, as observed in the SPR assays (Figure 4B) and by the increase in FP (Figure 5B). At this time, since DNA has been pushed to the new channel, it is not kinked any more but kept relatively rigid by the MutL ${ }^{\mathrm{LN} 40}$ binding. This, and interaction of the fluorophore itself with bound protein, can explain the lowered FRET. A similar straightening of DNA relative to the unbound DNA was previously observed upon ATP-dependent MutS release in SAXS experiments using DNA labelled with gold-clusters (Hura et al., 2013a). The effect is also present to lesser extent when using a mixture of MutS ${ }^{\Delta \mathrm{C} 800}$ with WT MutL in this setup (Figure 5-figure supplement 1C). The result indicates that MutL ${ }^{\mathrm{LN} 40}$ loading occurs after mismatch recognition and sliding clamp formation by MutS ${ }^{\Delta \mathrm{C} 800}$.

Since we observed that upon sliding clamp formation, MutS loads MutL onto DNA, we wondered whether this DNA loading step is essential for MMR. Indeed we observed a correlation with the DNA binding ability of MutL for MutH activation (Figure 5C). Moreover, the DNA-binding mutants of MutL impair in vivo MMR (Robertson et al., 2006) (Figure 5D, Table 2), indicating that loading of MutL onto DNA after mismatch recognition is essential for MMR.

\section{Discussion}

Taken together, our data reveal how the large conformational changes within MutS after mismatch recognition promote MMR activation. In the mismatch and ATP activated state MutS pushes DNA into a new channel, which allows sliding of the protein over DNA. The new state with the clamps crossed over the DNA explains the stability of the MutS sliding clamp on DNA (Schofield et al., 2001; Lebbink et al., 2010; Jeong et al., 2011), as electrostatic interactions between DNA and the positive charges lining the new channel may stabilize the new clamp conformation. The conformational change pushes the connector domain away from the center and on top of the ATPase domains, to provide a second interface for the MutL protein that binds to the opposing MutS subunit, while DNA in the new MutS channel can also contribute to MutL binding. This loads the N-terminal domains of MutL onto the DNA and the MutL binding delays the sliding of MutS (Figure 5E, Video 2). The loading step of MutL onto DNA is required for MutH activation and nicking (Figure 5C) (Junop et al., 2003; Robertson et al., 2006), while UvrD loading and activation at this nick (Yamaguchi et al., 1998) would follow similar validation. In this way, the requirement of the MutS conformational change for full MutL interaction is a sophisticated validation mechanism, which presumably is conserved in the eukaryotic homologs. It ensures that repair is only initiated when necessary, and due to the MMR system DNA replication can be completed with few errors incorporated in the genome.

The complete transition from mismatch binding to sliding clamp state is likely to take multiple steps (Qiu et al., 2012). First a single ATP will bind, leading to a stabilized asymmetric nucleotide state of MutS on the mismatch (Antony and Hingorani, 2004; Antony et al., 2006; Monti et al., 2011), followed by binding of the second ATP (Mazur et al., 2006; Hargreaves et al., 2010). Meanwhile MutS will undergo two separate ATP-induced events, the tilting of the subunits that push DNA into a new channel and the rearrangement of the connector domain (and the associated mismatch binding domain) that together generate a new MutL interface.

These two movements could potentially be uncoupled. MutS binding to a non-hydrolysable ATP analog can already cause a closed clamp-like state, (i.e. perform the tilting movement) as supported by SAXS analysis (Hura et al., 2013b), but may possibly not change the conformation of the mismatched binding domain (Qiu et al., 2012), as consequence of the connector domain movement. This would explain how MutS with ATP $\gamma$ S (or with ATP for a mutant that cannot hydrolyse nucleotides 


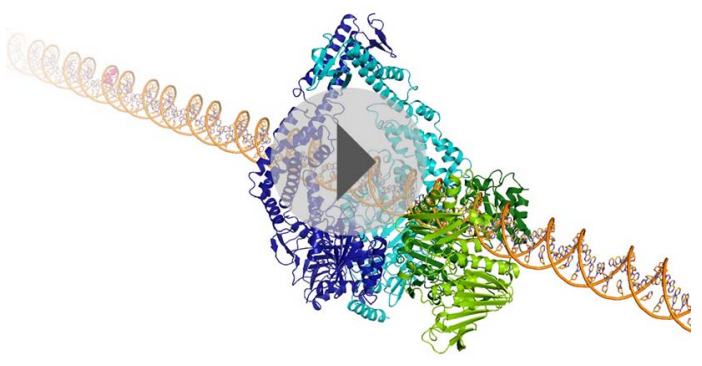

Video 2. Model for initiation of DNA mismatch repair. After MutS (cyan/blue) has recognized a mismatch in DNA (in orange; mismatch shown as pink spheres), it will bind ATP which triggers a conformational change in which the subunits tilt across each other and the connector domains move outward. This pushes the DNA to a new channel, where MutS fits as a loose ring around the DNA duplex and can behave as a sliding clamp. The N-terminal domain of MutL (green) can specifically recognize this state by binding two interfaces simultaneously. This loads MutL onto the DNA, where the $\mathrm{N}$-terminal domains could dimerize and downstream effectors can be activated.

DOl: 10.7554/eLife.06744.018
[E694A] [Jacobs-Palmer and Hingorani, 2007]) could form a closed clamp state that can no longer be loaded onto DNA (Gradia et al., 1999; Jacobs-Palmer and Hingorani, 2007; Cristóvão et al., 2012), but nevertheless is not sufficient to bind MutL.

Our data do not address the order of the two events, tilting and connector movement, or how they relate to the two ATP binding events. Observed conformational changes resulting in ternary complex and sliding clamp formation have previously been suggested to be independent (Mendillo et al., 2010). Indeed our structure does suggest that rearrangement of a single connector domain (in the subunit equivalent to the 'MSH2' subunit; (Mendillo et al., 2009) is sufficient for the complex formation with MutL $\alpha$ (Hess et al., 2006; Hargreaves et al., 2010, 2012). This might allow MSH6 to initially remain bound to the mismatch, consistent with models that consider transient asymmetric nucleotide states involved in mismatch verification and possibly ternary complex formation (Antony and Hingorani, 2004; Hess et al., 2006; Lebbink et al., 2006; Mazur et al., 2006; Hargreaves et al., 2010; Monti et al., 2011; Qiu et al., 2012). Another question that is unclear is where the loading of MutL onto DNA takes place. It could occur on or close to the mismatch itself, but it is also possible that MutS first slides before loading MutL on DNA.

Once the sliding clamp conformation is reached, the complex no longer interacts with the mismatch (Gorman et al., 2012). The clamp state loads MutL onto DNA, stabilizes a straight form of the DNA (Figure 5B) (Hura et al., 2013a) and triggers the conformational changes of MutL. These involve movements in the C-terminal domains (Guarné et al., 2004) to form a ring around the DNA and ATP binding by the N-terminal domains of MutL to generate the state that activates MutH and UvrD (Prolla et al., 1994; Drotschmann et al., 1998; Ban et al., 1999; Acharya et al., 2003).

In conclusion, we have used single-cysteine mutants and chemical crosslinking to trap and analyze a relevant MMR intermediate state that has long been elusive. This sliding clamp state of MutS bound to a MutL domain is highly informative. It corresponds to a reaction intermediate that occurs during a series of conformational changes triggered by mismatch recognition, and explains why specifically this conformation of MutS is able to recruit MutL. The presented combination of structural and biophysical methods provides a powerful approach to resolve conformational changes within large and transient protein complexes that form and act during biologically relevant processes.

\section{Materials and methods}

\section{Proteins}

MutS mutants were created in the mutS gene in vector pET-3D (Lamers et al., 2000; Giron-Monzon et al., 2004; Manelyte et al., 2006; Winkler et al., 2011) or vector pET15b (Manelyte et al., 2006; Winkler et al., 2011) (for His-tagged MutS constructs in FRET assays). MutL mutants were generated in the mutL gene in plasmid pTX418 (Feng and Winkler, 1995; Ban and Yang, 1998). Single-cysteine MutS and MutL constructs were obtained as described (Giron-Monzon et al., 2004; Groothuizen et al., 2013). Mutant and WT MutS and MutL proteins were purified as described previously (Lamers et al., 2000; Manelyte et al., 2006), except that in the buffers $\mathrm{KCl}$ was used instead of $\mathrm{NaCl}$ (final gel filtration buffer for MutS: $25 \mathrm{mM}$ Hepes pH 7.5, $150 \mathrm{mM} \mathrm{KCl}, 1 \mathrm{mM} \mathrm{DTT}$; for MutL: $20 \mathrm{mM}$ Tris pH 8.0, $0.5 \mathrm{M} \mathrm{KCl}, 10 \%$ glycerol, $1 \mathrm{mM}$ DTT). 
MutH was purified as follows: E. coli BL21(DE3) cells were transformed with MutH expression plasmid pTX417 (Feng and Winkler, 1995) and plated onto LB agar with $50 \mu \mathrm{g} / \mathrm{ml}$ carbenicillin. A colony was picked and cells were grown in LB with $50 \mu \mathrm{g} / \mathrm{ml}$ carbenicillin at $37^{\circ} \mathrm{C}$ to OD600 0.6 and induced with $1 \mathrm{mM}$ isopropyl 1-thio- $\beta$-D-galactopyranoside for $4 \mathrm{hr}$. Cells were harvested and resuspended in binding buffer $(25 \mathrm{mM}$ Tris $\mathrm{pH} 8.0,300 \mathrm{mM} \mathrm{KCl}, 10 \mathrm{mM}$ imidazole, $0.2 \mathrm{mM}$ DTT) with $1 \mathrm{mM}$ PMSF and protease inhibitors (Roche Diagnostics, F. Hoffmann-La Roche Ltd, Switzerland) and lysed by sonication. The cleared supernatant was incubated with Talon resin (Clonetech Laboratories, Takara holdings inc, Japan) for $30 \mathrm{~min}$ on ice. Beads were washed using binding buffer with $1 \mathrm{M} \mathrm{KCl}$, and MutH was eluted with $250 \mathrm{mM}$ imidazole in binding buffer. The His-tag was removed by cleavage with Thrombin protease ( 5 units thrombin/mg MutH; GE Healthcare, Fairfield, California) while dialyzing against $20 \mathrm{mM}$ Tris $\mathrm{pH} 8.0,100 \mathrm{mM} \mathrm{KCl}, 0.2 \mathrm{mM} \mathrm{DTT}$ for $2 \mathrm{hr}$ at $22^{\circ} \mathrm{C}$ followed by overnight incubation at $4^{\circ} \mathrm{C}$. The mixture was brought to $20 \mathrm{mM}$ imidazole, incubated with Talon beads to remove uncleaved protein, and loaded onto a heparin column equilibrated in buffer $\mathrm{A}$ ( $25 \mathrm{mM}$ Tris $\mathrm{pH}$ 8.0, $0.1 \mathrm{M} \mathrm{KCl}, 1 \mathrm{mM}$ DTT). MutH was eluted using a gradient of $0.1-1.0 \mathrm{M} \mathrm{KCl}$ in buffer $\mathrm{A}$, pooled and diluted twofold with buffer $A$ and loaded onto a MonoQ column equilibrated with buffer $A$. MutH was eluted using the same gradient, pooled and dialyzed overnight against $25 \mathrm{mM}$ MES pH 5.5, $150 \mathrm{mM}$ $\mathrm{KCl}, 1 \mathrm{mM}$ DTT. MutH was loaded onto a MonoS column equilibrated with $25 \mathrm{mM} \mathrm{MES} \mathrm{pH} \mathrm{5.5,} 0.1 \mathrm{M}$ $\mathrm{KCl}, 1 \mathrm{mM}$ DTT and eluted using a $0.1-1.0 \mathrm{M} \mathrm{KCl}$ gradient. Peak fractions were pooled, concentrated using Centriprep 10 and loaded onto a Superdex 75 column equilibrated with $25 \mathrm{mM}$ Tris pH 8.0, 250 $\mathrm{mM} \mathrm{KCl}, 1 \mathrm{mM}$ DTT. Peak fractions were pooled, concentrated, flash frozen in $25 \mathrm{mM}$ Tris pH 8.0, 250 $\mathrm{mM} \mathrm{KCl}, 1 \mathrm{mM} \mathrm{DTT}, 50 \%$ glycerol and stored at $-80^{\circ} \mathrm{C}$.

\section{Small-scale protein crosslinking}

Single cysteine MutS ${ }^{\Delta C 800}$ and His-tagged MutL ${ }^{\mathrm{LN} 40}$ proteins were reduced with $10 \mathrm{mM}$ DTT for $20 \mathrm{~min}$ and $\mathrm{O} / \mathrm{N}$ dialyzed into buffer $\mathrm{B}(25 \mathrm{mM}$ Hepes $\mathrm{pH} 7.5,400 \mathrm{mM} \mathrm{KCl}, 5 \mathrm{mM} \mathrm{MgCl}, 10 \%$ glycerol) at $4^{\circ} \mathrm{C}$, to remove DTT. MutS ${ }^{\Delta \mathrm{C} 800}(0.57 \mu \mathrm{M})$ was incubated with 100-bp DNA containing a G:T mismatch (AAACAGGCTTAGGCTGGAGCTGAAGCTTAGCTTAGGATCATCGAGGATCGAGCTC GGTGCAATTCAGCGGTACCCAATTCGCCCTATAGGCATCCAGGTT annealed with AACCTGGAT GCCTATAGGGCGAATTGGGTACCGCTGAATTGCACCGAGCTTGATCCTCGATGATCCTAAGCTAAG CTTCAGCTCCAGCCTAAGCCTGTTT, $0.29 \mu \mathrm{M}$ ) for $25 \mathrm{~min}$ on ice in buffer $\mathrm{C}(25 \mathrm{mM}$ Hepes pH 7.5, $125 \mathrm{mM} \mathrm{KCl}, 5 \mathrm{mM} \mathrm{MgCl}$ ). MutL ${ }^{\mathrm{LN} 40}(4 \mu \mathrm{M})$ was incubated with $5 \mathrm{mM}$ ATP for 25 min on ice. MutS ${ }^{\Delta \mathrm{C} 800 / D N A}$

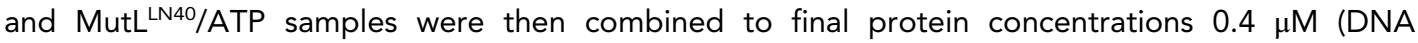
concentration $0.2 \mu \mathrm{M}$ ) and additional ATP was added to a final concentration of $1 \mathrm{mM}$. Samples were then incubated for $10 \mathrm{~min}$ at RT, after which they were adjusted to $37^{\circ} \mathrm{C}$ for $2 \mathrm{~min}$. Crosslinker (BMOE or $\mathrm{BM}[\mathrm{PEO}]_{3}$, Pierce, Thermo Fisher scientific, Waltham, MA, dissolved to $0.5 \mathrm{mM}$ in DMSO) was added to a final concentration of $50 \mu \mathrm{M}$ and samples were incubated for exactly 2 min at $37^{\circ} \mathrm{C}$. Reactions were stopped by adding protein loading buffer with DTT and crosslinking was assessed on SDS-PAGE gels stained with coomassie.

\section{MutS ${ }^{\Delta C 800} / M^{4} L^{L N 40}$ complex purification}

To obtain crystallizable amounts of crosslinked MutS ${ }^{\Delta \mathrm{C} 800} / \mathrm{MutL}^{\mathrm{LN} 40}$ complex, equimolar amounts of

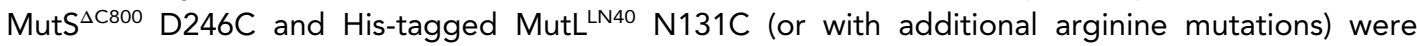
reduced and dialyzed separately, as described above. MutL ${ }^{\mathrm{LN} 40}$ was diluted to $2 \mu \mathrm{M}$ in buffer D (25 mM Hepes pH 7.5, $400 \mathrm{mM} \mathrm{KCl}, 10 \%$ glycerol) and incubated with a 5 -fold molar excess of BM $(\mathrm{PEO})_{3}$ (from $50 \mathrm{mM}$ solution in DMSO) for $10 \mathrm{~min}$ at $4^{\circ} \mathrm{C}$. The low MutL ${ }^{\mathrm{LN} 40}$ concentration prevented the formation of MutL ${ }^{\mathrm{LN} 40}-$ MutL ${ }^{\mathrm{LN} 40}$ crosslinks, while the excess crosslinker ensured each MutL ${ }^{\mathrm{LN} 40}$ to react with one maleimid group so that the other reactive side of the crosslinker remained available. The MutL LN40 was then bound to Talon beads and the beads were subsequently washed with 20 column volumes of buffer $D$ and 20 column volumes of buffer $E(25 \mathrm{mM} \mathrm{Hepes} \mathrm{pH} 7.5,150 \mathrm{mM} \mathrm{KCl}$, $10 \%$ glycerol, $5 \mathrm{mM}$ imidazole) to remove excess crosslinker. MutS ${ }^{\Delta C 800}$ was incubated for 10 min with equimolar amounts of 30-bp DNA with a G:T mismatch at position 9 (AGCTGCCAGGCACCAGTGT CAGCGTCCTAT annealed with ATAGGACGCTGACACTGGTGCTTGGCAGCT) in buffer C. The DNA-bound MutS ${ }^{\Delta \mathrm{C} 800}$ was then added to the Talon-bound MutL ${ }^{\bar{L} 40}$, and 30 -fold excess ATP was immediately added after which everything was incubated to crosslink for $1 \mathrm{hr}$ at $4^{\circ} \mathrm{C}$. The beads were then washed with 10 column volumes buffer $\mathrm{E}$ to remove MutS ${ }^{\Delta \mathrm{C}^{800}}$-MutS ${ }^{\Delta \mathrm{C} 800}$ crosslinks, after which 
the protein was eluted in buffer E with $300 \mathrm{mM}$ imidazole and DTT was added to quench excess crosslinker. The protein was bound to a $5 \mathrm{ml}$ heparin column (GE Healthcare, Fairfield, California) and eluted with a $0.1-1 \mathrm{M} \mathrm{KCl}$ gradient, which removed the DNA from the protein. The elution was subsequently concentrated and purified with size-exclusion chromatography in buffer $\mathrm{B}$ containing 1 mM DTT, for which two S200 16/60 columns were coupled resulting in one long column. The

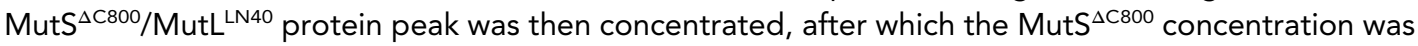
estimated using $\varepsilon=95,238$ and the whole process (including DTT incubation and dialysis) was repeated to obtain $S_{2} L_{2}$ complexes. The resulting protein (5-10\% final yield) was concentrated to 80-90 $\mu \mathrm{M}$ (expressed in MutS monomer concentrations; $\varepsilon=94,660$ ) and flash-frozen until further use.

\section{Crystallization and structure solution}

For crystallization, $50 \mu \mathrm{M}$ MutS $\mathrm{SC}^{\mathrm{C} 800} / \mathrm{MutL}^{\mathrm{LN} 40}$ complex was incubated with $25 \mu \mathrm{M}$ DNA containing a G:T mismatch (27-bp: TGCCAGGCACCAGTGTCAGCGTCCTAT annealed with ATAGGACGCTGA CACTGGTGCITGGCA or 100-bp, same sequence as above) for $25 \mathrm{~min}$ on ice. AMP-PNP was subsequently added to a concentration of $1 \mathrm{mM}$ and the protein was crystallized at $4^{\circ} \mathrm{C}$ using vapor diffusion in 9-12\% PEG-8000, $100 \mathrm{mM}$ Tris $\mathrm{pH} 7.0,200 \mathrm{mM} \mathrm{MgCl}_{2}$, and $80-450 \mathrm{mM}$ sodium malonate. Microseeding was used to increase crystal nucleation. Crystals were cryoprotected in mother liquor supplemented with $25 \%$ ethylene glycol and $100 \mathrm{mM} \mathrm{KCl}$ before flash-cooling in liquid nitrogen. Diffraction data were collected at $100 \mathrm{~K}$ at beamline ID-29 at the ESRF or beamline PX-III at the SLS.

Crystallographic data were processed with XDS (Kabsch, 2010) or iMOSFLM (Powell et al., 2013) and scaled using Aimless from the CCP4 suite (Winn et al., 2011). Crystal structures were solved in consecutive steps of finding domains using Phaser (McCoy et alo, 2007). Several search models were used, but best results were obtained with domains from chain A of PDB entry 1W7A as search models for MutS ${ }^{\Delta C 800}$ and chain A from PDB entry $1 B K N$ for MutL ${ }^{L N 40}$, while clear density for residues 150-164 of MutL ${ }^{\text {LN40 }}$ allowed building as in PDB entry $1 \mathrm{NHJ}$. The search process was improved by going back and forth between the different datasets to find missing domains. Initial structure solution was performed starting from crystal form 1 as follows: first, a search model consisting of residues 267-800 of chain A of PDB entry 1W7A (MutS) was searched twice using Phaser, which resulted in a solution with these chains forming a tilted MutS dimer. Next, this solution was used together with a search model consisting of chain A of $1 \mathrm{BKN}$ (MutL ${ }^{\mathrm{LN4O}}$ ), which placed this protein against the ATPase domain of one MutS subunit. Then, the second MutLLN40 was found with Phaser using a brute rotation search of $15^{\circ}$ around the angle that would orient this MutL $\mathrm{L}^{\mathrm{LN} 40}$ on the other side of the MutS dimer in a similar manner as the first, and automated translation, packing and refinement steps by Phaser indeed placed the MutL ${ }^{\mathrm{LN} 40}$ in the symmetrically equivalent position. One connector domain (residues 128-266 of chain A of 1W7A) was then found with Phaser, and the second connector domain was placed using similar steps as for the second MutL ${ }^{\mathrm{LN} 40}$ search. Thus the search identified the equivalent dimeric counterpart three times for separate parts of the complex (the main MutS chain, MutL ${ }^{\operatorname{LN} 40}$ and connector domains). The resulting MutS-MutL ${ }^{\mathrm{LN} 40}$ complex structure could then be used as a search model in all crystal forms and easily identified equivalent complexes in each of those (present three times in the asymmetric units in the $6.6 \AA$ and $7.6 \AA$ datasets). Finally, for crystal form 1, an additional 'half complex' was found with Phaser using one MutS chain and one MutL ${ }^{L N 40}$ chain of the existing complex structure. This second complex forms a symmetry-generated dimer over a twofold axis, with similar MutS-MutL ${ }^{\mathrm{LN} 40}$ interfaces, but the MutS clamp domains in this crystallographic dimer could not be modeled. This second conformer forms a more compact MutS dimer, probably due to crystal packing, but since it has identical interfaces with MutL ${ }^{\mathrm{LN} 40}$ we focussed on the main conformation throughout this paper. Excellent quality of the structure solutions after molecular replacement with the complete but unrefined models is evident from the Phaser statistics: TFZ $=9.0 / L L G=996$ for 4.7 $\AA$; TFZ $=14.2 / \mathrm{LLG}=899$ for $6.6 \AA$; and TFZ $=13.0 / \mathrm{LLG}=795$ for the $7.6 \AA$ dataset.

Refinement was first performed using rigid body refinement in REFMAC5 (Murshudov et al., 1997, 2011), for which the following domains of MutS were defined: residues 128-266, 267-765, 766-800; and for MutL: residues 20-204, 205-331. Next, limited restrained refinements were performed, first using ProSMART-generated external restraints (Nicholls et alo, 2012) to the PDB_REDO-optimized (Joosten et al., 2012) entries of chain A of 1W7A and chain A of 1BKN in order to ensure consistency with prior observations, followed by TLS and jelly-body refinement in latter stages. PDB_REDO-optimized homologues were used for external restraint generation in order to 
maximize reliability of the prior structural information. All refinements were performed using REFMAC5 (Murshudov et alo, 1997, 2011). During refinement, clear density became visible for missing residues 150-164 of the MutL ${ }^{\mathrm{LN} 40}$ subunits, which followed the conformation of PDB entry $1 \mathrm{NHJ}$. Interestingly, this conformation was different from that in the MutL search model state, indicating this to be real signal, and not due to bias from the search model. Also, AMP-PNP could be placed in density in the nucleotide binding sites of MutS. During intermediate stages, PDB_REDO and MolProbity (Chen et alo, 2010) were used to correct geometry and perform side-chain flips. After refinement, all structures were in the 97th-100th Clashscore and 98th-100th MolProbity score percentiles. Refinement and data collection statistics can be found in Table 1. Figures and videos were generated with MacPyMOL (http://www.pymol.org), interpolations between conformations were created with LSQMAN (Kleywegt and Jones, 1994) and electrostatic surface with CCP4mg (Winn et alı, 2011). Protein interface areas were calculated using PISA (Winn et al., 2011) for which the missing loop of residues $126-131$ of MutL ${ }^{\mathrm{LN} 40}$ in interface 2 was modeled as in PDB entry $1 \mathrm{NHJ}$.

\section{MutS conformational changes}

To look at changes within MutS dimers, we used MutS D835R dimer (Manelyte et alo, 2006; Groothuizen et al., 2013) variants that do not form tetramers, with single cysteines in positions R449C (His-tagged), D246C, S798C, or A336C. The proteins were labeled with Alexa Fluor 488 or Alexa Fluor 594 maleimide (Invitrogen, Thermo Fisher scientific, Waltham, MA) according to the manufacturers instruction. Excessive dye was removed using Zeba Spin Desalting columns (Thermo Fisher scientific, Waltham, MA) and the degree of labeling determined from the absorbance spectra recorded from 220-700 $\mathrm{nm}$ (nanodrop) according to the manufactures instructions.

Clamp-domain crossover movement and connector domain movement within MutS dimers were measured using FRET in which fluorescence emission spectra were recorded with excitation at either $485 \mathrm{~nm}$ ( $5 \mathrm{~nm}$ slit width) for FRET or $590 \mathrm{~nm}$ ( $5 \mathrm{~nm}$ slit width) for direct acceptor measurements. FRET was determined by the ratio between signal at 485 and $615 \mathrm{~nm}$ while direct acceptor was determined by the ratio between signal at 590 and $615 \mathrm{~nm}$ and after correction for spectral crosstalk the ratio FRET/acceptor was calculated, and normalized for unbound protein. Heterodimers of single-cysteine MutS variants labeled with Alexa Fluor 488 and Alexa Fluor 594, respectively, were allowed to form by mixing $200 \mathrm{nM}$ of each protein and incubation at $22^{\circ} \mathrm{C}$ for at least $30 \mathrm{~min}$ in the absence of ADP in buffer $\mathrm{F}(25 \mathrm{mM}$ Hepes $\mathrm{pH} 7.2,150 \mathrm{mM} \mathrm{KCl}$ and $5 \mathrm{mM} \mathrm{MgCl}$ ) supplemented with $0.05 \%$ TWEEN-20. Next, $200 \mathrm{nM}$ of 59-bp DNA with a G:T mismatch (TGAAGCTTAGCTTAGGATCATCGAGGATCG AGCTCGGTGCAATTCAGCGGTACCCAATT annealed with AATTGGGTACCGCTGAATTGCACCGA GCTIGATCCTCGATGATCCTAAGCTAAGCTTCA, with blocked ends as described above) was added, followed by addition of $1 \mathrm{mM}$ ATP. As a homoduplex control $240 \mathrm{pM} \lambda$-DNA (corresponding to $200 \mathrm{nM}$ of the 59 bp blocked Heteroduplex-DNA) was used.

MutS-DNA FRET was measured in a Hitachi Fluorescence spectrofluorimeter F-4500 (Hitachi Ltd, Japan) (Program FL Solutions 2.0). Fluorescence emission spectra $(600-700 \mathrm{~nm})$ were recorded with excitation at either $435 \mathrm{~nm}$ ( $5 \mathrm{~nm}$ slit width) for FRET or $590 \mathrm{~nm}$ ( $5 \mathrm{~nm}$ slit width) for direct acceptor measurements. FRET was determined by the ratio between signal at 435 and $615 \mathrm{~nm}$ while direct acceptor was determined by the ratio between signal at 590 and $615 \mathrm{~nm}$ and after correction for spectral crosstalk the ratio FRET/acceptor was calculated. We used 30-bp DNA with or without a G:T mismatch (AATTGCACCGAGCTTGATCCTCGATGATCC annealed with complementary strand or GGATCATCGAGGATCGAGCTCGGTGCAATT), where the T-containing strand had $5^{\prime}$ and $3^{\prime}$ digoxigenin labels so that both DNA ends were blocked with anti-digoxigenin Fab fragments (Roche Diagnostics, F. Hoffmann-La Roche Ltd, Switzerland). $100 \mathrm{nM}$ of the DNA with $6 \mu \mathrm{M}$ SYTOX Blue (Invitrogen, Thermo Fisher scientific, Waltham, MA) was mixed with 200 nM MutS variants labeled with Alexa Fluor 594 in buffer F, after which ATP was added to $1 \mathrm{mM}$ to induce the conformational change in MutS.

\section{In vivo MMR complementation}

Spontaneous mutation rates were assessed using acquired rifampicin resistance. Strains KR1517 (mutS, as in [Lamers et al., 2004]) or GM4250 (gift from M Marinus, [Aronshtam and Marinus, 1996]) (mutL) were transformed with empty vector or plasmid containing WT or mutant MutS or His-MutL 
genes, and plated on LB/agar plates with $50 \mu \mathrm{g} / \mathrm{ml}$ carbenicillin and $30 \mu \mathrm{g} / \mathrm{ml}$ kanamycin. After overnight incubation at $37^{\circ} \mathrm{C}$, single colonies were picked and grown in $10 \mathrm{ml} \mathrm{LB}$ with antibiotics to $\mathrm{OD}_{600} \sim 1.0$. Next, $0.33 \times 10^{8}$ or $1 \times 10^{8}$ cells were plated on LB plates with antibiotics and $0.1 \mathrm{mg} / \mathrm{ml}$ rifampicin. Plates were $\mathrm{O} / \mathrm{N}$ incubated at $37^{\circ} \mathrm{C}$ and rifampicin resistant colonies were counted. Mutation rates and $95 \%$ confidence intervals were determined using Fluctuation AnaLysis CalculatOR with the MSS maximum-likelihood method (http://www.mitochondria.org/protocols/FALCOR.html).

\section{DNA binding kinetics}

SPR experiments for binding MutS ${ }^{\Delta \mathrm{C} 800} \mathrm{D} 246 \mathrm{C}$ or crosslinked MutS $\mathrm{SC800}^{\mathrm{C}}$ MutL ${ }^{\mathrm{LN} 40}$ complex to DNA were performed in a Biacore T200 system (GE Healthcare, Fairfield, CA) as described (Groothuizen et alı, 2013). The experiments were performed in SPR buffer containing $25 \mathrm{mM}$ Hepes pH 7.5, 150 $\mathrm{mM} \mathrm{KCl}, 5 \mathrm{mM} \mathrm{MgCl}$, $1 \mathrm{mM}$ DTT, 0.05\% TWEEN-20 and $1 \mathrm{mM} \mathrm{ATP,} \mathrm{using} \mathrm{immobilized} \mathrm{biotinylated}$ 100-bp DNA (same sequence as above) with a fluorescein moiety at the other end.

\section{MutL-MutS binding assay}

Full-length $\mathrm{His}_{6}$-MutL binding to the full-length MutS sliding clamp was assessed using a two-step SPR assay. The resulting graphs are not strictly affinity curves, as changes in MutS stability on DNA contribute to the observed response, but serve to assess the effect of mutations. The SPR buffer was supplemented with $20 \%$ glycerol to ensure MutL stability. Before every measurement, anti-fluorescein Fab fragment (Invitrogen, Thermo Fisher scientific, Waltham, MA) was injected to block the fluorescein-labeled DNA (100 bp, see above) ends. MutS sliding clamps were captured on the endblocked DNA by injecting $200 \mathrm{nM}$ WT or mutant MutS protein (in buffer with $1 \mathrm{mM} \mathrm{ATP)} \mathrm{for} 120 \mathrm{~s}$. Then WT or mutant MutL protein (in buffer with $1 \mathrm{mM} \mathrm{ATP)} \mathrm{was} \mathrm{injected} \mathrm{for} 120 \mathrm{~s}$, followed by dissociation with buffer only. This was repeated with varying concentrations of MutL.

\section{DNA binding by MutL}

Fluorescence polarization measurements to assess DNA-binding of MutL ${ }^{\mathrm{LN} 40}$ mutants were performed in low-salt FP buffer with $25 \mathrm{mM}$ Hepes $\mathrm{pH} 7.5,50 \mathrm{mM} \mathrm{KCl}, 5 \mathrm{mM} \mathrm{MgCl} 2,1 \mathrm{mM}$ DTT and $0.05 \%$ TWEEN-20. For full length MutL, the buffer was supplemented with $10 \%$ glycerol. A concentration of $0.5 \mathrm{nM}$ of $5^{\prime}$ labeled TAMRA-41-bp DNA (ATAGGACGCTGACACTGGTGCTTGGCAGCTTCTAATTCGAT annealed with complementary strand) was used. MutL proteins were serial diluted in black 96-well microplates (PerkinElmer Inc, Waltham, MA) in $100 \mu$ l volumes. Polarization of the TAMRA label was read out in a PHERAstar FS machine (BMG Labtech GmbH, Germany) with an 540/590 (excitation/ emission) FP module.

\section{DNA kinking assays}

Stopped-flow assays to assess DNA binding and kinking were performed in buffer containing $25 \mathrm{mM}$ Hepes $\mathrm{pH}$ 7.5, $150 \mathrm{mM} \mathrm{KCl}, 5 \mathrm{mM} \mathrm{MgCl}, 1 \mathrm{mM}$ DTT, 0.05\% TWEEN-20 and $10 \mu \mathrm{M}$ ADP, with or without $1 \mathrm{mM}$ ATP. One syringe contained $100 \mathrm{nM}$ of 45-bp DNA with or without a G:T mismatch (GTCATCCTCG[T*]CTCAAGCTGCCAGGCACCAGTGTCAGCGTCCTAT annealed with complementary strand or ATAGGACGC[T*]GACACTGGTGCITGGCAGCTTGAGACGAGGATGAC) which was either labeled with Alexa Fluor 594 at position 11 in the top strand and Alexa Fluor 488 at position 10 in the bottom strand (indicated by $T^{\star}$ ), or with $5^{\prime}$-labeled with TAMRA in the top strand. The other syringe contained $400 \mathrm{nM}$ MutS ${ }^{\Delta \mathrm{C} 800} \mathrm{D} 246 \mathrm{C}$ or crosslinked MutS ${ }^{\Delta \mathrm{C} 800} /$ MutL $^{\mathrm{LN} 40}$ complex. For assays with double-labeled DNA, donor fluorophores were excited at $473 \mathrm{~nm}$ and measured using filters $540 \mathrm{IB}+540 \mathrm{IK}$, while acceptor fluorophores were measured at the same time using an OG590 filter. For experiments with TAMRA-labeled DNA, the fluorophore was excited at $545 \mathrm{~nm}$ and OG540 filters were used for read-out. Samples were co-injected in a KinetAsyst SF-61DX2 stopped-flow machine (TgK Scientific, UK) fitted with R10699 photomultiplier tubes (Hamamatsu Photonics K.K., Japan) at $15^{\circ} \mathrm{C}$ and measured for $100 \mathrm{~s}$, which was repeated 5-10 times and averages were calculated.

\section{MutH activation assay}

Circular DNA containing a single G:T mismatch and 12 hemi-methylated GATC sites was prepared via primer extension on single stranded DNA from a derivative of pGEM-13Zf (gift from J Jiricny) as 
described (Baerenfaller et al., 2006) with the exception that closed circular DNA was purified from gel using a Wizard gel purification kit (Promega Corporation, Madison, WI). To enable quantification, an Alexa Fluor 647 labeled oligo (IBA GmbH, Germany) was used: CCAGACGTCTGTCGACGTTGGGAAGCT[T*]GAGTATTCTATAGTGTCACCT, where the $\mathrm{G}$ is nucleotide forming a G:T mismatch and the $T^{*}$ is the Alexa Fluor 647 labeled nucleotide. Nicking reactions contained $25 \mathrm{mM}$ Hepes $\mathrm{KOH} \mathrm{pH}$ $7.5,150 \mathrm{mM} \mathrm{KCl}, 0.1 \mathrm{mg} / \mathrm{ml} \mathrm{BSA}, 5 \mathrm{mM} \mathrm{MgCl}, 1 \mathrm{mM}$ DTT, $1 \mathrm{mM}$ ATP, $0.5 \mathrm{nM}$ circular DNA, $200 \mathrm{nM}$ MutS, 200 nM WT MutL, single-cysteine MutL N131C, MutL N131C R266E or MutL N131C R162E/R266E/R316E and $100 \mathrm{nM} \mathrm{MutH}$ as well as twofold dilutions thereof. Control reactions contained either no protein or $200 \mathrm{nM}$ MutS and $100 \mathrm{nM}$ MutH. Reactions were incubated for $5 \mathrm{~min}$ at $37^{\circ} \mathrm{C}$ and stopped with an equal volume of $20 \%$ glycerol, $1 \%$ SDS and 50 mM EDTA. Samples were analyzed on $0.8 \%$ agarose gels supplemented with $1 \mu \mathrm{g} / \mathrm{ml}$ ethidium bromide, run in $1 \mathrm{x}$ TAE. Conversion of covalently closed circles into nicked product was visualized using the fluorescence of the Alexa Fluor 647 label using a Typhoon Trio Imager (GE Healthcare, Fairfield, CA) with excitation at $633 \mathrm{~nm}$ and emission filter 670BP30.

\section{ATPase assay}

ATPase activity of WT MutS and MutS P595A/I597A/M759D was measured by coupling ATP hydrolysis to oxidation of NADH as in (Lamers et alo, 2004). MutS protein $(5 \mu \mathrm{M})$ was mixed with 3.125-500 $\mu \mathrm{M}$ ATP and hydrolysis was measured in a spectrophotometer during $5 \mathrm{~min}$.

\section{MutL ${ }^{\text {LN40 }}$ dimerization assay}

Crosslinked MutS ${ }^{\Delta C 800 / M u t L}{ }^{L N 40}$ complex $(1 \mathrm{mg} / \mathrm{ml})$ was incubated for $5 \mathrm{~min}$ on ice with equimolar amounts of 100-bp DNA containing a G:T mismatch (sequence as in main text). MutL LN40 $(2 \mathrm{mg} / \mathrm{ml})$

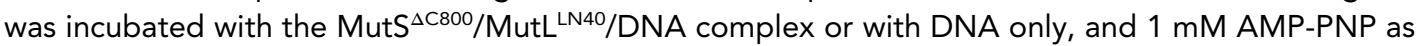
described (Ban and Yang, 1998). Samples were injected onto a S200 5/150 column in buffer containing $20 \mathrm{mM}$ Tris pH 8.0, $150 \mathrm{mM} \mathrm{KCl}, 0.1 \mathrm{mM}$ EDTA, $5 \mathrm{mM} \mathrm{MgCl} 2,1 \mathrm{mM}$ DTT and $5 \%$ glycerol. Eluted fractions were analyzed on SDS-PAGE stained with coomassie.

\section{Acknowledgements}

We are grateful for contributions of group members, to Randy Read for assistance with molecular replacement, and to Lea Geissert, Miguel Keidel, Gaelle Cyriale Ngatcheu Famou, Rosine Djamfa and Matthias Trohart for assistance with FRET assays. We thank Jacques Neefjes, Hein te Riele and Thijn Brummelkamp for critical reading of the manuscript. Structure coordinates have been deposited in the Protein Data Bank under accession codes 5AKB, 5AKC, 5AKD. This research was funded by European Community's Seventh Framework Programme mismatch2model HEALTH-F4-2008-223545, the Centre for Biomedical Genetics, and NWO-CW ECHO 711.011.011 (to TS) and VIDI 700.58.428 (to $\mathrm{JL}$ ). The authors declare to have no competing interests.

\section{Additional information}

Funding

\begin{tabular}{lll} 
Funder & Grant reference & Author \\
\hline European Commission & $\begin{array}{l}\text { mismatch2model } \\
\text { HEALTH-F4-2008-223545 }\end{array}$ & $\begin{array}{l}\text { Joyce HG Lebbink, Peter } \\
\text { Friedhoff, Titia K Sixma }\end{array}$ \\
\cline { 2 - 3 } $\begin{array}{l}\text { Ministerie van Onderwijs, } \\
\begin{array}{l}\text { Cultuur en } \\
\text { Wetenschappen }\end{array}\end{array}$ & $\begin{array}{l}\text { Center for Biomedical } \\
\text { Genetics }\end{array}$ & Titia K Sixma \\
\hline $\begin{array}{l}\text { Nederlandse Organisatie } \\
\text { voor Wetenschappelijk } \\
\text { Onderzoek }\end{array}$ & CW Echo 711.011.011 & Titia K Sixma \\
\hline $\begin{array}{l}\text { Nederlandse Organisatie } \\
\text { voor Wetenschappelijk } \\
\text { Onderzoek }\end{array}$ & CW VIDI 700.58.428 & Joyce HG Lebbink \\
\hline
\end{tabular}

The funders had no role in study design, data collection and interpretation, or the decision to submit the work for publication. 
Author contributions

FSG, Performed and designed molecular biology, biophysical, structural and in vivo assays, and wrote the manuscript with contributions from TKS, AF, JHGL and PF; IW, Contributed initial MutS/ MutL crosslinking; MC, ADM, Set up FRET experiments with labeled MutS and stopped-flow experiments; AF, Contributed and designed SPR and stopped-flow biophysics; HHKW, Contributed to biochemical and in vivo assays; AR, Contributed to initial MutS/MutL crosslinking; $\mathrm{NH}$, Contributed the MutH activation assay; RAN, GNM, Contributed to structure refinement; JHGL, Contributed the MutH activation assay and contributed to supervision of the study; PF, Designed all tools, supervised FRET experiments and contributed to supervision of the study; TKS, Supervised the study with contributions from JHGL and PF

\section{Additional files}

Major datasets

The following datasets were generated:

\begin{tabular}{|c|c|c|c|c|}
\hline Author(s) & Year & Dataset title & $\begin{array}{l}\text { Dataset ID } \\
\text { and/or URL }\end{array}$ & $\begin{array}{l}\text { Database, license, and } \\
\text { accessibility information }\end{array}$ \\
\hline $\begin{array}{l}\text { Groothuizen FS, Winkler I, } \\
\text { Cristovao M, Fish A, } \\
\text { Winterwerp HHK, Reumer } \\
\text { A, Marx AD, Hermans N, } \\
\text { Nicholls RA, Murshudov } \\
\text { GN, Lebbink JHG, } \\
\text { Friedhoff P, Sixma TK }\end{array}$ & 2015 & $\begin{array}{l}\text { MutS in complex with the } \\
\text { N-terminal domain of } \\
\text { MutL_crystal form } 1\end{array}$ & $\begin{array}{l}\text { http://www.rcsb.org/pdb/ } \\
\text { explore/explore.do? } \\
\text { structureld=5akb }\end{array}$ & $\begin{array}{l}\text { Publicly available at the } \\
\text { RSCB Protein Data Bank } \\
\text { (Accession no 5AKB). }\end{array}$ \\
\hline $\begin{array}{l}\text { Groothuizen FS, Winkler I, } \\
\text { Cristovao M, Fish A, } \\
\text { Winterwerp HHK, Reumer } \\
\text { A, Marx AD, Hermans N, } \\
\text { Nicholls RA, Murshudov } \\
\text { GN, Lebbink JHG, } \\
\text { Friedhoff P, Sixma TK }\end{array}$ & 2015 & $\begin{array}{l}\text { MutS in complex with the } \\
\text { N-terminal domain of } \\
\text { MutL_crystal form } 2\end{array}$ & $\begin{array}{l}\text { http://www.rcsb.org/pdb/ } \\
\text { explore/explore.do? } \\
\text { structureld=5akc }\end{array}$ & $\begin{array}{l}\text { Publicly available at the } \\
\text { RSCB Protein Data Bank } \\
\text { (Accession no 5AKC). }\end{array}$ \\
\hline $\begin{array}{l}\text { Groothuizen FS, Winkler I, } \\
\text { Cristovao M, Fish A, } \\
\text { Winterwerp HHK, Reumer } \\
\text { A, Marx AD, Hermans N, } \\
\text { Nicholls RA, Murshudov } \\
\text { GN, Lebbink JHG, } \\
\text { Friedhoff P, Sixma TK }\end{array}$ & 2015 & $\begin{array}{l}\text { MutS in complex with the } \\
\text { N-terminal domain of } \\
\text { MutL_crystal form } 3\end{array}$ & $\begin{array}{l}\text { http://www.rcsb.org/pdb/ } \\
\text { explore/explore.do? } \\
\text { structureld=5akd }\end{array}$ & $\begin{array}{l}\text { Publicly available at the } \\
\text { RSCB Protein Data Bank } \\
\text { (Accession no 5AKD). }\end{array}$ \\
\hline
\end{tabular}

Standard used to collect data: PDB validation reports are supplied.

\section{References}

Acharya S, Foster PL, Brooks P, Fishel R. 2003. The coordinated functions of the E. coli MutS and MutL proteins in mismatch repair. Molecular Cell 12:233-246. doi: 10.1016/S1097-2765(03)00219-3.

Allen DJ, Makhov A, Grilley M, Taylor J, Thresher R, Modrich P, Griffith JD. 1997. MutS mediates heteroduplex loop formation by a translocation mechanism. The EMBO Journal 16:4467-4476. doi: 10.1093/emboj/16.14. 4467.

Antony E, Hingorani MM. 2004. Asymmetric ATP binding and hydrolysis activity of the Thermus aquaticus MutS dimer is key to modulation of its interactions with mismatched DNA. Biochemistry 43:13115-13128. doi: 10. 1021/bi049010t.

Antony E, Khubchandani S, Chen S, Hingorani MM. 2006. Contribution of Msh2 and Msh6 subunits to the asymmetric ATPase and DNA mismatch binding activities of Saccharomyces cerevisiae Msh2-Msh6 mismatch repair protein. DNA Repair 5:153-162. doi: 10.1016/j.dnarep.2005.08.016.

Aronshtam A, Marinus MG. 1996. Dominant negative mutator mutations in the mutL gene of Escherichia coli. Nucleic Acids Research 24:2498-2504. doi: 10.1093/nar/24.13.2498.

Baerenfaller K, Fischer F, Jiricny J. 2006. Characterization of the "mismatch repairosome" and its role in the processing of modified nucleosides in vitro. Methods in Enzymology 408:285-303.

Ban C, Junop M, Yang W. 1999. Transformation of MutL by ATP binding and hydrolysis: a switch in DNA mismatch repair. Cell 97:85-97. doi: 10.1016/S0092-8674(00)80717-5.

Ban C, Yang W. 1998. Crystal structure and ATPase activity of MutL: implications for DNA repair and mutagenesis. Cell 95:541-552. doi: 10.1016/S0092-8674(00)81621-9.

Bende SM, Grafström RH. 1991. The DNA binding properties of the MutL protein isolated from Escherichia coli. Nucleic Acids Research 19:1549-1555. doi: 10.1093/nar/19.7.1549. 
Biswas I, Obmolova G, Takahashi M, Herr A, Newman MA, Yang W, Hsieh P. 2001. Disruption of the helix-u-turnhelix motif of MutS protein: loss of subunit dimerization, mismatch binding and ATP hydrolysis. Journal of Molecular Biology 305:805-816. doi: 10.1006/jmbi.2000.4367.

Chen VB, Arendall WB, Headd JJ, Keedy DA, Immormino RM, Kapral GJ, Murray LW, Richardson JS, Richardson DC. 2010. MolProbity: all-atom structure validation for macromolecular crystallography. Acta Crystallographica. Section D, Biological Crystallography 66:12-21. doi: 10.1107/S0907444909042073.

Cho WK, Jeong C, Kim D, Chang M, Song KM, Hanne J, Ban C, Fishel R, Lee JB. 2012. ATP alters the diffusion mechanics of MutS on mismatched DNA. Structure 20:1264-1274. doi: 10.1016/j.str.2012.04.017.

Cristóvão M, Sisamakis E, Hingorani MM, Marx AD, Jung CP, Rothwell PJ, Seidel CAM, Friedhoff P. 2012. Singlemolecule multiparameter fluorescence spectroscopy reveals directional MutS binding to mismatched bases in DNA. Nucleic Acids Research 40:5448-5464. doi: 10.1093/nar/gks138.

Deshpande RA, Williams GJ, Limbo O, Williams RS, Kuhnlein J, Lee JH, Classen S, Guenther G, Russell P, Tainer JA, Paull TT. 2014. ATP-driven Rad50 conformations regulate DNA tethering, end resection, and ATM checkpoint signaling. The EMBO Journal 33:482-500. doi: 10.1002/embj.201386100.

Drotschmann K, Aronshtam A, Fritz HJ, Marinus MG. 1998. The Escherichia coli MutL protein stimulates binding of Vsr and MutS to heteroduplex DNA. Nucleic Acids Research 26:948-953. doi: 10.1093/nar/26.4.948.

Elez M, Radman M, Matic I. 2012. Stoichiometry of MutS and MutL at unrepaired mismatches in vivo suggests a mechanism of repair. Nucleic Acids Research 40:3929-3938. doi: 10.1093/nar/gkr1298.

Feng G, Winkler ME. 1995. Single-step purifications of His6-MutH, His6-MutL and His6-MutS repair proteins of Escherichia coli K-12. Biotechniques 19:956-965.

Giron-Monzon L, Manelyte L, Ahrends R, Kirsch D, Spengler B, Friedhoff P. 2004. Mapping protein-protein interactions between MutL and MutH by cross-linking. The Journal of Biological Chemistry 279:49338-49345. doi: 10.1074/jbc.M409307200.

Gorman J, Wang F, Redding S, Plys AJ, Fazio T, Wind S, Alani EE. 2012. Single-molecule imaging reveals targetsearch mechanisms during DNA mismatch repair. Proceedings of the National Academy of Sciences of USA 109: E3074-E3083. doi: 10.1073/pnas.1211364109.

Gradia S, Acharya S, Fishel R. 1997. The human mismatch recognition complex hMSH2-hMSH6 functions as a novel molecular switch. Cell 91:995-1005. doi: 10.1016/S0092-8674(00)80490-0.

Gradia S, Subramanian D, Wilson T, Acharya S, Makhov A, Griffith J, Fishel R. 1999. hMSH2-hMSH6 forms a hydrolysis-independent sliding clamp on mismatched DNA. Molecular Cell 3:255-261. doi: 10.1016/S10972765(00)80316-0.

Grilley M, Welsh KM, Su SS, Modrich P. 1989. Isolation and characterization of the Escherichia coli mutL gene product. The Journal of Biological Chemistry 264:1000-1004.

Groothuizen FS, Fish A, Petoukhov MV, Reumer A, Manelyte L, Winterwerp HHK, Marinus MG, Lebbink JHG, Svergun DI, Friedhoff P, Sixma TK. 2013. Using stable MutS dimers and tetramers to quantitatively analyze DNA mismatch recognition and sliding clamp formation. Nucleic Acids Research 41:8166-8181. doi: 10.1093/nar/gkt582.

Guarné A, Ramon-Maiques S, Wolff EM, Ghirlando R, Hu X, Miller JH, Yang W. 2004. Structure of the MutL Cterminal domain: a model of intact MutL and its roles in mismatch repair. The EMBO Journal 23:4134-4145. doi: 10.1038/sj.emboj.7600412.

Hall MC, Matson SW. 1999. The Escherichia coli MutL protein physically interacts with MutH and stimulates the MutH-associated endonuclease activity. The Journal of Biological Chemistry 274:1306-1312. doi: 10.1074/jbc. 274.3.1306.

Hall MC, Wang H, Erie DA, Kunkel TA. 2001. High affinity cooperative DNA binding by the yeast Mlh1-Pms1 heterodimer. Journal of Molecular Biology 312:637-647. doi: 10.1006/jmbi.2001.4958.

Hargreaves VV, Putnam CD, Kolodner RD. 2012. Engineered disulfide-forming amino acid substitutions interfere with a conformational change in the mismatch recognition complex Msh2-Msh6 required for mismatch repair. The Journal of Biological Chemistry 287:41232-41244. doi: 10.1074/jbc.M112.402495.

Hargreaves VV, Shell SS, Mazur DJ, Hess MT, Kolodner RD. 2010. Interaction between the Msh2 and Msh6 nucleotide-binding sites in the Saccharomyces cerevisiae Msh2-Msh6 complex. The Journal of Biological Chemistry 285:9301-9310. doi: 10.1074/jbc.M109.096388.

Hess MT, Mendillo ML, Mazur DJ, Kolodner RD. 2006. Biochemical basis for dominant mutations in the Saccharomyces cerevisiae MSH6 gene. Proceedings of the National Academy of Sciences of USA 103:558-563. doi: 10.1073/pnas.0510078103.

Hombauer H, Srivatsan A, Putnam CD, Kolodner RD. 2011. Mismatch repair, but not heteroduplex rejection, is temporally coupled to DNA replication. Science 334:1713-1716. doi: 10.1126/science.1210770.

Hopfner KP, Karcher A, Shin DS, Craig L, Arthur LM, Carney JP, Tainer JA. 2000. Structural biology of Rad50 ATPase: ATP-driven conformational control in DNA double-strand break repair and the ABC-ATPase superfamily. Cell 101:789-800. doi: 10.1016/S0092-8674(00)80890-9.

Hopfner KP, Tainer JA. 2003. Rad50/SMC proteins and ABC transporters: unifying concepts from high-resolution structures. Current Opinion in Structural Biology 13:249-255. doi: 10.1016/S0959-440X(03)00037-X.

Hura GL, Budworth H, Dyer KN, Rambo RP, Hammel M, McMurray CT, Tainer JA. 2013b. Comprehensive macromolecular conformations mapped by quantitative SAXS analyses. Nature Methods 10:453-454. doi: 10.1038/nmeth.2453.

Hura GL, Tsai C-L, Claridge SA, Mendillo ML, Smith JM, Williams GJ, Mastroianni AJ, Alivisatos AP, Putnam CD, Kolodner RD, Tainer JA. 2013a. DNA conformations in mismatch repair probed in solution by X-ray scattering from gold nanocrystals. Proceedings of the National Academy of Sciences of USA 110:17308-17313. doi: 10. 1073/pnas. 1308595110. 
Jacobs-Palmer E, Hingorani MM. 2007. The effects of nucleotides on MutS-DNA binding kinetics clarify the role of MutS ATPase activity in mismatch repair. Journal of Molecular Biology 366:1087-1098. doi: 10.1016/j.jmb.2006. 11.092 .

Jeong C, Cho WK, Song KM, Cook C, Yoon TY, Ban C, Fishel R, Lee JB. 2011. MutS switches between two fundamentally distinct clamps during mismatch repair. Nature Structural \& Molecular Biology 18:379-385. doi: 10.1038/nsmb.2009.

Jiricny J. 2013. Postreplicative mismatch repair. Cold Spring Harbor Perspectives in Biology 5:a012633. doi: 10. 1101/cshperspect.a012633.

Joosten RP, Joosten K, Murshudov GN, Perrakis A. 2012. PDB_REDO: constructive validation, more than just looking for errors. Acta Crystallographica. Section D, Biological Crystallography 68:484-496. doi: 10.1107/ S0907444911054515.

Junop MS, Yang W, Funchain P, Clendenin W, Miller JH. 2003. In vitro and in vivo studies of MutS, MutL and MutH mutants: correlation of mismatch repair and DNA recombination. DNA Repair 2:387-405. doi: 10.1016/S15687864(02)00245-8.

Kabsch W. 2010. Integration, scaling, space-group assignment and post-refinement. Acta Crystallographica. Section D, Biological Crystallography 66:133-144. doi: 10.1107/S0907444909047374.

Kadyrov FA, Dzantiev L, Constantin N, Modrich P. 2006. Endonucleolytic function of MutLalpha in human mismatch repair. Cell 126:297-308. doi: 10.1016/j.cell.2006.05.039.

Kleywegt GJ, Jones TA. 1994. A super position. CCP4/ESF-EACBM Newsletter Protein Crystallography 31:9-14.

Krishna TS, Kong XP, Gary S, Burgers PM, Kuriyan J. 1994. Crystal structure of the eukaryotic DNA polymerase processivity factor PCNA. Cell 79:1233-1243. doi: 10.1016/0092-8674(94)90014-0.

Kunkel TA, Erie DA. 2005. DNA mismatch repair. Annual Review of Biochemistry 74:681-710. doi: 10.1146/ annurev.biochem.74.082803.133243.

Lamers MH, Georgijevic D, Lebbink JH, Winterwerp HHK, Agianian B, de Wind N, Sixma TK. 2004. ATP increases the affinity between MutS ATPase domains: Implications for ATP hydrolysis and conformational changes. The Journal of Biological Chemistry 279:43879-43885. doi: 10.1074/jbc.M406380200.

Lamers MH, Perrakis A, Enzlin JH, Winterwerp HHK, de Wind N, Sixma TK. 2000. The crystal structure of DNA mismatch repair protein MutS binding to a G x T mismatch. Nature 407:711-717.

Lebbink JHG, Fish A, Reumer A, Natrajan G, Winterwerp HHK, Sixma TK. 2010. Magnesium coordination controls the molecular switch function of DNA mismatch repair protein MutS. The Journal of Biological Chemistry 285: 13131-13141. doi: 10.1074/jbc.M109.066001.

Lebbink JHG, Georgijevic D, Natrajan G, Fish A, Winterwerp HHK, Sixma TK, de Wind N. 2006. Dual role of MutS glutamate 38 in DNA mismatch discrimination and in the authorization of repair. The EMBO Journal 25:409-419. doi: 10.1038/sj.emboj.7600936.

Lenhart JS, Pillon MC, Guarné A, Simmons LA. 2013. Trapping and visualizing intermediate steps in the mismatch repair pathway in vivo. Molecular Microbiology 90:680-698. doi: 10.1111/mmi.12389.

Lynch HT, de la Chapelle A. 1999. Genetic susceptibility to non-polyposis colorectal cancer. Journal of Medical Genetics 36:801-818.

Manelyte L, Urbanke C, Giron-Monzon L, Friedhoff P. 2006. Structural and functional analysis of the MutS C-terminal tetramerization domain. Nucleic Acids Research 34:5270-5279. doi: 10.1093/nar/gkl489.

Mazur DJ, Mendillo ML, Kolodner RD. 2006. Inhibition of Msh6 ATPase activity by mispaired DNA induces a Msh2 (ATP)-Msh6(ATP) state capable of hydrolysis-independent movement along DNA. Molecular Cell 22:39-49. doi: 10.1016/j.molcel.2006.02.010.

McCoy AJ, Grosse-Kunstleve RW, Adams PD, Winn MD, Storoni LC, Read RJ. 2007. Phaser crystallographic software. Journal of Applied Crystallography 40:658-674. doi: 10.1107/S0021889807021206.

Mendillo ML, Hargreaves VV, Jamison JW, Mo AO, Li S, Putnam CD, Woods VL Jr, Kolodner RD, Woods VL, Kolodner RD. 2009. A conserved MutS homolog connector domain interface interacts with MutL homologs. Proceedings of the National Academy of Sciences of USA 106:22223-22228. doi: 10.1073/pnas.0912250106.

Mendillo ML, Mazur DJ, Kolodner RD. 2005. Analysis of the interaction between the Saccharomyces cerevisiae MSH2-MSH6 and MLH1-PMS1 complexes with DNA using a reversible DNA end-blocking system. The Journal of Biological Chemistry 280:22245-22257. doi: 10.1074/jbc.M407545200.

Mendillo ML, Putnam CD, Mo AO, Jamison JW, Li S, Woods VL, Kolodner RD. 2010. Probing DNA- and ATPmediated conformational changes in the MutS family of mispair recognition proteins using deuterium exchange mass spectrometry. The Journal of Biological Chemistry 285:13170-13182. doi: 10.1074/jbc.M110. 108894.

Monti MC, Cohen SX, Fish A, Winterwerp HHK, Barendregt A, Friedhoff P, Perrakis A, Heck AJR, Sixma TK, van den Heuvel RHH, Lebbink JH. 2011. Native mass spectrometry provides direct evidence for DNA mismatchinduced regulation of asymmetric nucleotide binding in mismatch repair protein MutS. Nucleic Acids Research 39:8052-8064. doi: 10.1093/nar/gkr498.

Murshudov GN, Skubák P, Lebedev AA, Pannu NS, Steiner RA, Nicholls RA, Winn MD, Long F, Vagin AA. 2011. REFMAC5 for the refinement of macromolecular crystal structures. Acta Crystallographica. Section D, Biological Crystallography 67:355-367. doi: 10.1107/S0907444911001314.

Murshudov GN, Vagin AA, Dodson EJ. 1997. Refinement of macromolecular structures by the maximum-likelihood method. Acta Crystallographica. Section D, Biological Crystallography 53:240-255. doi: 10.1107/ S0907444996012255.

Nicholls RA, Long F, Murshudov GN. 2012. Low-resolution refinement tools in REFMAC5. Acta Crystallographica. Section D, Biological Crystallography 68:404-417. doi: 10.1107/S090744491105606X. 
Obmolova G, Ban C, Hsieh P, Yang W. 2000. Crystal structures of mismatch repair protein MutS and its complex with a substrate DNA. Nature 407:703-710. doi: 10.1038/35037509.

Plotz G, Raedle J, Brieger A, Trojan J, Zeuzem S. 2003. N-terminus of hMLH1 confers interaction of hMutL $\alpha$ and hMutL $\beta$ with hMutS $\alpha$. Nucleic Acids Research 31:3217-3226. doi: 10.1093/nar/gkg420.

Powell HR, Johnson O, Leslie AGW. 2013. Autoindexing diffraction images with iMosflm. Acta Crystallographica. Section D, Biological Crystallography 69:1195-1203. doi: 10.1107/S0907444912048524.

Prolla TA, Pang Q, Alani E, Kolodner RD, Liskay RM. 1994. MLH1, PMS1, and MSH2 interactions during the initiation of DNA mismatch repair in yeast. Science 265:1091-1093. doi: 10.1126/science.8066446.

Qiu R, DeRocco VC, Harris C, Sharma A, Hingorani MM, Erie DA, Weninger KR. 2012. Large conformational changes in MutS during DNA scanning, mismatch recognition and repair signalling. The EMBO Journal 31: 2528-2540. doi: 10.1038/emboj.2012.95.

Robertson A, Pattishall SR, Matson SW. 2006. The DNA binding activity of MutL is required for methyl-directed mismatch repair in Escherichia coli. The Journal of Biological Chemistry 281:8399-8408. doi: 10.1074/jbc. M509184200.

Schofield MJ, Nayak S, Scott TH, Du C, Hsieh P. 2001. Interaction of Escherichia coli MutS and MutL at a DNA mismatch. The Journal of Biological Chemistry 276:28291-28299. doi: 10.1074/jbc.M103148200.

Schorzman AN, Perera L, Cutalo-Patterson JM, Pedersen LC, Pedersen LG, Kunkel TA, Tomer KB. 2011. Modeling of the DNA-binding site of yeast Pms1 by mass spectrometry. DNA Repair 10:454-465. doi: 10.1016/j.dnarep. 2011.01.010.

Warren JJ, Pohlhaus TJ, Changela A, lyer RR, Modrich PL, Beese LS. 2007. Structure of the human MutS $\alpha$ DNA lesion recognition complex. Molecular Cell 26:579-592. doi: 10.1016/j.molcel.2007.04.018.

Williams GJ, Williams RS, Williams JS, Moncalian G, Arvai AS, Limbo O, Guenther G, SilDas S, Hammel M, Russell P, Tainer JA. 2011. ABC ATPase signature helices in Rad50 link nucleotide state to Mre11 interface for DNA repair. Nature Structural \& Molecular Biology 18:423-431. doi: 10.1038/nsmb.2038.

Winkler I, Marx AD, Lariviere D, Heinze R, Cristóvão M, Reumer A, Curth U, Sixma TK, Friedhoff P. 2011. Chemical trapping of the dynamic MutS-MutL complex formed in DNA mismatch repair in Escherichia coli. The Journal of Biological Chemistry 286:17326-17337. doi: 10.1074/jbc.M110.187641.

Winn MD, Ballard CC, Cowtan KD, Dodson EJ, Emsley P, Evans PR, Keegan RM, Krissinel EB, Leslie AGW, McCoy A, McNicholas SJ, Murshudov GN, Pannu NS, Potterton EA, Powell HR, Read RJ, Vagin A, Wilson KS. 2011. Overview of the CCP4 suite and current developments. Acta Crystallographica. Section D, Biological Crystallography 67:235-242. doi: 10.1107/S0907444910045749.

Yamaguchi M, Dao V, Modrich P. 1998. MutS and MutL activate DNA helicase II in a mismatch-dependent manner. The Journal of Biological Chemistry 273:9197-9201. doi: 10.1074/jbc.273.15.9197. 